\title{
Novelty and target processing during an auditory novelty oddball: A simultaneous event-related potential and functional magnetic resonance imaging study
}

Citation for published version (APA):

Strobel, A., Debener, S., Sorger, B., Peters, J. C., Kranczioch, C., Hoechstetter, K., Engel, A. K., Brocke, B., \& Goebel, R. (2008). Novelty and target processing during an auditory novelty oddball: A simultaneous event-related potential and functional magnetic resonance imaging study. Neuroimage, 40(2), 869-883. https://doi.org/10.1016/j.neuroimage.2007.10.065

Document status and date:

Published: 01/01/2008

DOI:

10.1016/j.neuroimage.2007.10.065

Document Version:

Publisher's PDF, also known as Version of record

\section{Document license:}

Taverne

\section{Please check the document version of this publication:}

- A submitted manuscript is the version of the article upon submission and before peer-review. There can be important differences between the submitted version and the official published version of record. People interested in the research are advised to contact the author for the final version of the publication, or visit the DOI to the publisher's website.

- The final author version and the galley proof are versions of the publication after peer review.

- The final published version features the final layout of the paper including the volume, issue and page numbers.

Link to publication

\footnotetext{
General rights rights.

- You may freely distribute the URL identifying the publication in the public portal. please follow below link for the End User Agreement:

www.umlib.nl/taverne-license

Take down policy

If you believe that this document breaches copyright please contact us at:

repository@maastrichtuniversity.nl

providing details and we will investigate your claim.
}

Copyright and moral rights for the publications made accessible in the public portal are retained by the authors and/or other copyright owners and it is a condition of accessing publications that users recognise and abide by the legal requirements associated with these

- Users may download and print one copy of any publication from the public portal for the purpose of private study or research.

- You may not further distribute the material or use it for any profit-making activity or commercial gain

If the publication is distributed under the terms of Article 25fa of the Dutch Copyright Act, indicated by the "Taverne" license above, 


\title{
Novelty and target processing during an auditory novelty oddball: A simultaneous event-related potential and functional magnetic resonance imaging study
}

\author{
Alexander Strobel, ${ }^{\mathrm{a}, \mathrm{b}, *}$ Stefan Debener, ${ }^{\mathrm{c}, \mathrm{d}}$ Bettina Sorger, ${ }^{\mathrm{b}}$ Judith C. Peters, ${ }^{\mathrm{b}}$ \\ Cornelia Kranczioch, ${ }^{\mathrm{e}}$ Karsten Hoechstetter, ${ }^{\mathrm{f}}$ Andreas K. Engel, ${ }^{\mathrm{d}}$ \\ Burkhard Brocke, ${ }^{\mathrm{g}}$ and Rainer Goebel ${ }^{\mathrm{b}}$
}

\author{
${ }^{a}$ Department of Experimental Psychology II, Institute of Psychology, Johann Wolfgang Goethe University Frankfurt/Main, 60054 Frankfurt, Germany \\ ${ }^{\mathrm{b}}$ Department of Cognitive Neuroscience, Faculty of Psychology, Maastricht University, 6200 MD Maastricht, The Netherlands \\ ${ }^{\mathrm{c}}$ MRC Institute of Hearing Research, Royal South Hants Hospital, Southampton, SO14 0YG, United Kingdom \\ ${ }^{\mathrm{d}}$ Department of Neurophysiology and Pathophysiology, University Medical Center Hamburg-Eppendorf, 20246 Hamburg, Germany \\ ${ }^{\mathrm{e}}$ Department of Psychology, University of Portsmouth, Portsmouth, PO1 2DY, United Kingdom \\ ${ }^{\mathrm{f}}$ MEGIS Software, 82166 Gräfelfing, Germany \\ ${ }^{\mathrm{g}}$ Department of Psychology, Dresden University of Technology, 01062 Dresden, Germany
}

Received 20 June 2007; revised 13 September 2007; accepted 5 October 2007

Available online 15 December 2007

Recent evidence suggests that both spatiotemporally distinct and overlapping brain regions are involved in bottom-up- and topdown-driven attentional processing. However, existing studies are based on a variety of different approaches, including electroencephalography (EEG) and functional magnetic resonance imaging (fMRI), raising the question of how EEG and fMRI findings in this field are related to each other. The present study aimed at disentangling common from specific regions underlying bottom-up novelty-processing and top-down target-processing. Simultaneous EEG and fMRI recordings were employed to investigate how fMRIidentified brain regions contribute to event-related potential (ERP) signatures of novelty- and target-processing. Fourteen subjects performed a modified novelty oddball task in which either rare tones or novel sounds served as targets in different blocks, allowing us to separate novelty-related from mere distractor-related effects. ERP signatures of novelty- and target-processing could be identified, confirming previous research based on recordings outside the scanner. fMRI analyses revealed that, despite considerable overlap of regions activated during novelty- and target-processing, bilateral superior temporal and right inferior frontal areas showed pronounced activation related to novelty-processing. fMRI-informed ERP dipole seeding was used to integrate both signals. The source modeling results further implicated temporal and inferior frontal

\footnotetext{
* Corresponding author. Department of Experimental Psychology II, Institute of Psychology, Johann Wolfgang Goethe University Frankfurt/ Main, Mertonstr. 17, 60054 Frankfurt/Main, Germany. Fax: +49 69798 23457.

E-mail address: alex.strobel@gmx.de (A. Strobel).

Available online on ScienceDirect (www.sciencedirect.com).
}

sources in novelty-processing. Target-related fMRI activation on the other hand was confirmed in a network comprising distributed frontoparietal regions as well as bilateral caudate nucleus and cerebellum. Most regions identified by fMRI showed a contribution to target-related ERP signatures. This pattern of findings underscores the potential of simultaneous EEG/fMRI recordings for the spatiotemporal characterization of target- and novelty-processing. (C) 2007 Elsevier Inc. All rights reserved.

Keywords: Novelty-processing; Target-processing; Simultaneous EEG/ fMRI; Novelty P3; P3b

\section{Introduction}

Attention relies on the integrity of distributed brain systems that control voluntary and involuntary, stimulus-driven selection of behaviorally relevant information in order to establish and maintain goal-directed action (Corbetta and Shulman, 2002; Kastner and Ungerleider, 2000). Electro- and magnetoencephalographic approaches as well as functional imaging methods have provided important insights into the spatial and temporal organization of such top-down and bottom-up attentional processes and have demonstrated that both spatiotemporally distinct and overlapping processes are involved in voluntary and involuntary attention (see Bledowski et al., 2004a; Debener et al., 2005a, for recent examples). However, it is still an unresolved question how the results obtained with these different methodologies relate to each other. 
A common tool to examine the interplay between top-down and bottom-up attentional mechanisms is the auditory novelty oddball paradigm, where infrequent, unique environmental sounds are interspersed into a series of frequent standard and rare target sine tones. This paradigm allows the examination of both top-downdriven target-processing and bottom-up-driven novelty-processing, that is, the allocation of attention to task-irrelevant, but potentially behaviorally significant events. Previous event-related potential (ERP) research has related novelty-processing to the novelty P3, a frontocentrally distributed positive deflection, which peaks at around $300 \mathrm{~ms}$, habituates over time, and has been proposed to be a correlate of the orienting response reflecting involuntary attention switching (Escera et al., 2000; Friedman et al., 2001). In contrast, voluntary top-down target-processing has been commonly associated with the later peaking and posteriorly distributed P3b, which does not show marked habituation (Debener et al., 2002) and which has been associated with processes of context updating (Donchin and Coles, 1988) or event categorization (Kok, 2001).

However, rare targets also evoke a deflection spatiotemporally similar to the novelty P3 (the P3a), and novel nontargets also evoke a later peaking, slightly smaller P3b (Debener et al., 2005a; Dien et al., 2003; Spencer et al., 2001). This suggests that novelty P3 and $\mathrm{P} 3 \mathrm{~b}$ reflect partly overlapping attentional processes controlled by shared as well as specific brain regions.

Current knowledge on the neuroanatomical networks involved in novelty- and target-processing has been extensively reviewed in previous reports (e.g. Corbetta and Shulman, 2002; Bledowski et al., 2004a,b; Friedman et al., 2001; Herrmann and Knight, 2001). Altogether, several lines of evidence suggest a target detection network comprising frontal areas, the insula, superior temporal and inferior parietal regions, with the temporoparietal junction (TPJ) being most frequently observed to contribute to the P3b.

Concerning neuroanatomical substrates of novelty-processing and the novelty P3, lesion studies suggest a role of the frontal lobes (Daffner et al., 2000; Knight, 1984) as well as the hippocampus (Knight, 1996), while intracerebral recordings additionally point to contributions from cingulate, temporal and temporoparietal areas (Baudena et al., 1995; Halgren et al., 1995a,b). Source localization efforts using high-density EEG recordings also suggest the cingulate as a possible source of the novelty P3 (Debener et al., 2005a; Dien et al., 2003), whereas a magnetoencephalographic study localized the generator of the novelty P3 in superior temporal lobes (Alho et al., 1998). Functional magnetic resonance imaging (fMRI) studies using an auditory novelty oddball paradigm indicate that novel stimuli consistently evoke stronger activation mainly in inferior and middle frontal areas and precentral gyrus as well as in middle temporal gyrus (Kiehl et al., 2001, 2005). These studies also implicate additional brain regions in novelty-processing, including medial frontal areas, anterior and posterior cingulate, intraparietal lobule, precuneus and occipital areas, as well as subcortical regions like caudate, putamen and thalamus. To our knowledge, there is only one fMRI study that has addressed the issue of the generators of the auditory evoked novelty P3 (Opitz et al., 1999). Opitz and colleagues recorded EEG and fMRI data during an auditory novelty oddball in separate sessions and found novel sounds to activate superior temporal cortex and a right inferior frontal region in those subjects with a pronounced N4-like ERP component to identifiable novels. fMRI-informed dipole modeling further suggested that these regions generated the novelty P3. However, these results were obtained in a block design and are based on separate EEG and fMRI recordings, rendering it difficult to directly compare these findings with studies employing a genuine novelty oddball.

In the present study we employed a genuine auditory novelty oddball paradigm, that is, pseudo-randomized sequences of frequent standards, rare tones and novel environmental sounds. To ensure an optimal correspondence of the ERP data with the BOLD signal, we simultaneously collected EEG and imaging data. Our objective was to disentangle common from specific regions underlying bottom-up novelty-processing and top-down targetprocessing. Importantly, to separate novelty-related effects from merely distractor-related effects, we contrasted the "classical" novelty oddball, i.e. rare tone targets and novel environmental sound nontargets, with a "reversed" novelty oddball, where novel sounds were the targets and rare tones served as nontargets (Debener et al., 2005a; Gaeta et al., 2003). We expected fMRI activation related to novelty-processing to be present regardless of whether the novel sounds were targets or nontargets and activation related to target-processing to be observed regardless of whether the targets were rare tones or novel sounds. Based on the fMRI results, fMRI-informed ERP source modeling (see, e.g., Bledowski et al., 2004b, 2006) was performed to further elucidate possible generators of the auditory novelty $\mathrm{P} 3$ and the P3b.

\section{Materials and methods}

\section{Subjects}

Fourteen healthy right-handed individuals, with no history of psychiatric or neurological disorders, were recruited from students and staff of the University of Maastricht (7 women, mean age \pm SD: $26.0 \pm 3.9$ years, age range: $21-37$ years). All subjects gave written informed consent prior to the start of the experiment. The study was approved by the local ethics committee.

\section{Task and procedure}

The task comprised four runs of 280 auditory stimuli, presented via MR-compatible earphones (Siemens Medical Systems, Erlangen, Germany) using Presentation 9.0 (Neurobehavioral Systems, Albany, CA, USA). The stimuli were rare sine tones (probability $9 \%)$ and unique environmental sounds (9\%), which were interspersed into a series of frequent standard sine tones $(82 \%)$. The sine tones were $350 \mathrm{~Hz}$ and $650 \mathrm{~Hz}$ tones with $10 \mathrm{~ms}$ rise and fall time. The environmental sounds were taken from a set of sounds established by Schneider et al. (2008). As every environmental sound was presented only once, we will refer to this stimulus category as novel sounds. All stimuli had a duration of $400 \mathrm{~ms}$ and were presented in a pseudo-random order with a stimulus onset asynchrony varying between $1896 \mathrm{~ms}$ and $2104 \mathrm{~ms}$ in steps of $4 \mathrm{~ms}$. Four, five or six standard tones preceded each rare tone or novel sound.

There were two conditions: In condition A, subjects were instructed to silently count the occurrence of the novel sounds (=novel targets) and to ignore the rare tones (=rare nontargets); in condition B, subjects were instructed to count the rare tones (=rare targets) and to ignore the novel sounds (=novel nontargets). Each condition was presented two times, with the arrangement (ABBA or $\mathrm{BAAB}$ ) and the assignment of the two sine tone frequencies to the rare and to the standard tone class being counterbalanced across subjects. Each block lasted $\sim 9$ min, and subjects reported the target count in a 1-minute break between blocks and after the last 
block. Prior to each block, instructions were presented visually via a mirror mounted on the head coil. Stimulus presentation was synchronized with $\mathrm{fMRI}$ data acquisition by triggering the stimulus presentation with the MR pulse of the preceding volume.

\section{Simultaneous EEG/fMRI recording}

Imaging was performed on a 3-T Siemens Allegra Scanner (Siemens Medical Systems, Erlangen, Germany) using a standard head coil. First, a T1-weighted anatomical magnetization-prepared rapid acquisition gradient echo (MPRAGE) scan was performed $\left(\mathrm{TR}=2300 \mathrm{~ms} ; \mathrm{TE}=4.57 \mathrm{~ms}\right.$; flip angle: $12^{\circ}$; field of view: $256 \times 256 \mathrm{~mm}^{2}$; voxel size: $1 \times 1 \times 1 \mathrm{~mm}^{3}$; 192 slices). Second, four functional scans were acquired while the subjects performed the task. Twenty-four sagittal slices (in-plane resolution: $3.5 \times 3.5 \mathrm{~mm}^{2}$, slice thickness: $4 \mathrm{~mm}$; gap: $1 \mathrm{~mm}$ ) covering the entire brain were acquired in an interleaved order using an echo planar imaging (EPI) sequence $\left(\mathrm{TR}=2000 \mathrm{~ms}, \mathrm{TE}=30 \mathrm{~ms}\right.$, flip angle: $90^{\circ}$; field of view: $224 \times 224 \mathrm{~mm}^{2}$; matrix size: $\left.64 \times 64\right)$. Slice acquisition was performed during the first $1400 \mathrm{~ms}$ of each TR and was followed by a $600 \mathrm{~ms}$ no-acquisition period to complete the TR. This silent interval served to present the auditory stimuli, to visually monitor proper EEG recording and to obtain for each TR an EEG period not contaminated by gradient noise (see Debener et al., 2005b). In each block, 285 volumes were acquired.

A 64-channel high-input impedance amplifier system specifically designed for the MR environment was used (Brainproducts, Munich, Germany). The setup consisted of two 32-channel MR plus amplifiers powered by a rechargeable power unit. The amplifiers were placed directly behind the scanner bore inside the MR room, which allowed us to use short wires with a total length of about $1.2 \mathrm{~m}$ from recording electrodes to amplifier. Sintered Ag/ $\mathrm{AgCl}$ ring electrodes with built-in $5 \mathrm{k} \Omega$ resistors were used. Data were recorded from 62 equidistant scalp sites mounted in a cap system (Easycap, Falk Minow Services, Herrsching, Germany). Additional plastic electrode holders were tied into the cap at occipital scalp sites to improve subject comfort. Continuous data were also recorded from one electrode placed below the left eye to monitor eye blinks and another electrode placed at the lower back for electrocardiogram (ECG) recording. Electrode impedances were maintained below $20 \mathrm{k} \Omega$ before recordings. Data from all 64 channels were referenced to the vertex, recorded with a pass-band of $0.016-250 \mathrm{~Hz}$ and digitized with 5000 samples per second at 16-bit resolution. The amplified signal was transmitted via fiberoptic cables to a recording PC placed outside the MR room and was stored together with a TTL pulse from the MRI indicating the onset of each TR.

\section{fMRI analysis}

Data were analyzed with BrainVoyager QX 1.4 (Brain Innovation, Maastricht, The Netherlands). Data preprocessing comprised slice scan time correction by sinc interpolation, 3D motion correction by trilinear interpolation using the first volume of the first run as reference volume and temporal filtering with linear trend removal and a high pass filter of 3 cycles per time course. The first five volumes of each run were discarded to remove T1 saturation effects. Functional data were then aligned to the anatomical scans and transformed into Talairach space (Talairach and Tournoux, 1988), yielding a 4D data representation (volume time course).
The statistical analysis was based on the application of multiple regression analysis to time series of event-related functional activation (Friston et al., 1995). The general linear model (GLM) was computed from the 56 (14 subjects $\times 4$ runs per subject) $z$ normalized volume time courses. For all stimuli of interest, i.e. the rare targets, rare nontargets, novel targets and novel nontargets, box-car time courses with a value of 1 for the stimuli of interest and with values of 0 for the remaining time points were convolved with a theoretical hemodynamic response function (Boynton et al., 1996) and were entered as predictors into the design matrix of the study.

Regions of interest (ROIs) were selected based on the results of a fixed effects GLM with correction for serial correlation. By contrasting the summed effect of all four experimental conditions against baseline (i.e. the standard tones), a 3D statistical map was obtained. Because visualization at a Bonferroni-adjusted level of significance of $P_{\text {Bonf }} \leq 0.001$ resulted in widespread and partly overlapping activation of anatomically distinct brain regions, the $t$ threshold was successively raised until anatomically meaningful and separable ROI could be selected. The final $t$-threshold was $t$ $(15,568)=9.2, P_{\text {Bonf }} \leq 1.9 \times 10^{-15}$, except for anterior temporal, parietal and occipital ROIs $\left(t(15,568)=10.8, P_{\text {Bonf }} \leq 2.0 \times 10^{-22}\right)$ and middle and posterior temporal ROIs $(t(15,568)=12.8$, $P_{\text {Bonf }} \leq 1.2 \times 10^{-32}$ ), respectively, for which the $t$-threshold was raised even further to avoid interconnected, but anatomically meaningless clusters of activation. At the respective $t$-thresholds, non-overlapping ROIs with a minimum cluster size of 50 voxels were selected for subsequent ROI-based contrast analyses.

Contrast analyses for the selected ROIs were based on random effects GLMs of the $z$-normalized volume time courses, corrected for serial correlations. For each ROI, two of the eight possible contrasts were examined to identify areas involved in novelty- and target-processing: (1) novel sounds vs. rare tones, to determine differences in neuronal activation due to stimulus class regardless of whether the stimuli were targets or nontargets; (2) targets vs. nontargets, to assess target-specific activation, regardless of whether the stimuli were novels or rares. Furthermore, the rare targets vs. novel nontargets contrast was also inspected to examine within-run differences in neuronal activation when stimuli and target instructions corresponded to the classical novelty oddball paradigm. ROIs were considered to exhibit a distinct activation pattern related to novelty-processing (here and in the following also termed novelty-related activation) if the novel sounds vs. rare tones contrast was significant, the targets vs. nontargets contrast was not significant, and the rare targets vs. novel nontargets contrast was significant with a negative $t$-value, i.e. higher activation following novel nontargets than following rare targets. ROIs were considered to show a distinct activation pattern related to target-processing (target-related activation) if the targets vs. nontargets contrast was significant, the novel sounds vs. rare tones contrast was not significant, and the rare targets vs. novel nontargets contrast was significant with a positive $t$-value, i.e. higher activation following rare targets than following novel nontargets. For the resulting novelty- and target-related ROIs, the remaining possible contrasts as well as the event-related averages were inspected to scrutinize the categorization of these ROIs.

\section{ERP analysis}

EEG data were analyzed using BrainVision Analyzer 1.05 (Brainproducts, Munich, Germany) and EEGLAB 5 (www.sccn. 
Table 1

fMRI results: regions-of-interest (ROI) analyses

\begin{tabular}{|c|c|c|c|c|c|c|c|c|c|c|}
\hline \multirow[t]{3}{*}{$\mathrm{ROI}^{1}$} & & \multirow[t]{3}{*}{ BA } & \multicolumn{5}{|l|}{$\mathrm{FFX}^{2}$} & \multicolumn{3}{|c|}{ RFX (contrasts) ${ }^{3}$} \\
\hline & & & \multirow[t]{2}{*}{ Voxel } & \multirow[t]{2}{*}{$x$} & \multirow[t]{2}{*}{$y$} & \multirow[t]{2}{*}{$z$} & \multirow[t]{2}{*}{$t$} & \multirow{2}{*}{$\begin{array}{l}\text { Novel vs. } \\
\text { rare } \\
t\end{array}$} & \multirow{2}{*}{$\begin{array}{l}\text { Target vs. } \\
\text { nontarget } \\
t\end{array}$} & \multirow{2}{*}{$\begin{array}{l}\text { Rare target vs. } \\
\text { novel nontarget } \\
t\end{array}$} \\
\hline & & & & & & & & & & \\
\hline \multicolumn{11}{|l|}{ Frontal } \\
\hline $\mathrm{IFS}^{\mathrm{N}}$ & $\begin{array}{l}\mathrm{K} \\
\mathrm{R}\end{array}$ & $\begin{array}{l}9 \\
9 / 46\end{array}$ & $\begin{array}{l}928 \\
424\end{array}$ & $\begin{array}{l}40 \\
45\end{array}$ & $\begin{array}{l}31 \\
20\end{array}$ & $\begin{array}{l}29 \\
27\end{array}$ & $\begin{array}{l}10.2 \\
10.0\end{array}$ & $7.8^{* *}$ & $\begin{array}{l}3.3^{\prime \prime} \\
0.6\end{array}$ & $-4.7 * *$ \\
\hline \multirow[t]{2}{*}{ PrCS } & $\mathrm{R}$ & 6 & 2072 & 47 & 6 & 35 & 10.7 & $4.3^{* *}$ & $2.6^{*}$ & -1.1 \\
\hline & $\mathrm{L}$ & & 67 & -37 & 1 & 32 & 9.6 & $5.3^{* *}$ & $2.3^{*}$ & -1.7 \\
\hline \multirow{3}{*}{$\begin{array}{l}\text { FrMed }^{\mathbf{T}} \\
\text { postMFG }^{\mathbf{T}}\end{array}$} & $\mathrm{L} / \mathrm{R}$ & $6 / 32$ & 6694 & 2 & 6 & 50 & 12.4 & 1.7 & $5.7 * *$ & $4.2 * *$ \\
\hline & $\mathrm{R}$ & 6 & 532 & 33 & -5 & 60 & 9.6 & 0.7 & $2.8^{*}$ & $2.8^{*}$ \\
\hline & $\mathrm{L}$ & & 53 & -34 & -11 & 58 & 10.3 & 0.9 & $2.4^{*}$ & 2.0 \\
\hline postMFG2 & $\mathrm{L}$ & $4 / 6$ & 225 & -46 & -4 & 51 & 10.1 & 1.1 & $2.7^{*}$ & 1.8 \\
\hline \multirow[t]{2}{*}{ IFG } & $\mathrm{R}$ & 47 & 1303 & 48 & 16 & 1 & 12.5 & $2.6^{*}$ & $4.5^{* *}$ & 1.3 \\
\hline & $\mathrm{L}$ & & 498 & -48 & 14 & 0 & 10.3 & $2.6^{*}$ & $4.9^{* *}$ & 0.9 \\
\hline \multicolumn{11}{|l|}{ Temporal } \\
\hline \multirow[t]{2}{*}{$\operatorname{antSTG}^{\mathbf{N}}$} & $\mathrm{R}$ & 22 & 333 & 54 & 1 & 2 & 11.9 & $3.9^{* *}$ & 1.4 & $-2.5^{*}$ \\
\hline & $\mathrm{L}$ & & 828 & -51 & 4 & 2 & 12.6 & $3.8^{* *}$ & $3.4^{* *}$ & 0.1 \\
\hline $\operatorname{midSTG}^{\mathbf{N}}$ & $\mathrm{R}$ & $22 / 41 / 42$ & 2767 & 59 & -19 & 9 & 15.2 & $10.2^{* *}$ & 1.3 & $-6.3^{* *}$ \\
\hline & $\mathrm{L}$ & & 3392 & -54 & -21 & 10 & 14.9 & $13.7^{* *}$ & 1.4 & $-6.7^{* *}$ \\
\hline postSTG & $\mathrm{R}$ & 22 & 3936 & 57 & -36 & 9 & 15.6 & $9.4 * *$ & $3.3 * *$ & $-5.7 * *$ \\
\hline & $\mathrm{L}$ & & 2286 & -55 & -41 & 14 & 14.5 & $9.2^{* *}$ & $3.5^{* *}$ & $-3.5^{* *}$ \\
\hline Parietal & & & & & & & & & & \\
\hline antIPS $^{\mathbf{T}}$ & $\mathrm{R}$ & 40 & 506 & 47 & -41 & 51 & 11.9 & 1.7 & $5.2^{* *}$ & $3.0^{*}$ \\
\hline postIPS & $\mathrm{R}$ & $7 / 40$ & 1075 & 33 & -58 & 41 & 11.7 & 2.1 & $4.5^{* *}$ & 1.5 \\
\hline & $\mathrm{L}$ & & 594 & -29 & -60 & 37 & 11.5 & $3.0^{*}$ & $3.0^{*}$ & 0.5 \\
\hline $\mathrm{PrCu}$ & $\mathrm{R}$ & 7 & 1037 & 9 & -71 & 38 & 12.0 & 2.0 & $3.6^{* *}$ & 1.3 \\
\hline & $\mathrm{L}$ & & 1094 & -3 & -73 & 33 & 12.2 & 1.6 & $2.5^{*}$ & 0.8 \\
\hline Occipital & & & & & & & & & & \\
\hline $\mathrm{Cu}$ & $\mathrm{L} / \mathrm{R}$ & 18 & 1500 & 3 & -72 & 8 & 11.6 & 1.3 & $4.2 * *$ & 2.1 \\
\hline LG & $\mathrm{L} / \mathrm{R}$ & 18 & 712 & 2 & -82 & -4 & 10.1 & 1.8 & $3.6^{* *}$ & 1.6 \\
\hline & $\mathrm{L}$ & & 381 & -6 & -72 & -2 & 9.6 & $3.2^{* *}$ & $3.8^{* *}$ & 1.4 \\
\hline Cingulate & & & & & & & & & & \\
\hline postCing & $\mathrm{L} / \mathrm{R}$ & 23 & 1450 & 1 & -27 & 26 & 11.6 & $2.7^{*}$ & 1.8 & -0.6 \\
\hline Subcortical & & & & & & & & & & \\
\hline Caud $^{\mathbf{T}}$ & $\mathrm{R}$ & & 586 & 11 & 4 & 10 & 10.2 & 1.7 & $5.4^{* *}$ & $4.1 * *$ \\
\hline & $\mathrm{L}$ & & 316 & -10 & 0 & 11 & 9.8 & $3.6^{* *}$ & $6.1^{* *}$ & $2.9^{*}$ \\
\hline Put & $\mathrm{R}$ & & 1265 & 20 & 10 & 2 & 10.8 & $6.6^{* *}$ & $4.6^{* *}$ & 2.2 \\
\hline & $\mathrm{L}$ & & 1155 & -20 & 9 & 1 & 10.1 & $4.4 * *$ & $5.9^{* *}$ & $3.7 * *$ \\
\hline Th-antNc & $\mathrm{R}$ & & 173 & 5 & -6 & 10 & 10.2 & $3.7 * *$ & $4.0 * *$ & 2.0 \\
\hline Th-mdNc & $\mathrm{R}$ & & 836 & 9 & -15 & 11 & 11.2 & $3.3 * *$ & $2.6^{*}$ & 0.3 \\
\hline & $\mathrm{L}$ & & 633 & -9 & -15 & 12 & 10.8 & $3.5^{* *}$ & $2.5^{*}$ & -0.3 \\
\hline Insular & & & & & & & & & & \\
\hline Ins & $\mathrm{R}$ & & 2000 & 34 & 20 & 7 & 11.2 & 2.0 & $6.7^{* *}$ & $2.6^{*}$ \\
\hline & $\mathrm{L}$ & & 1709 & -33 & 18 & 7 & 10.8 & $2.6^{*}$ & $5.8^{* *}$ & $2.3^{*}$ \\
\hline inflns ${ }^{\mathbf{N}}$ & $\mathrm{R}$ & & 63 & 40 & -2 & -8 & 10.0 & $5.1^{* *}$ & 1.9 & $-2.4^{*}$ \\
\hline & $\mathrm{L}$ & & 80 & -39 & -3 & -8 & 9.8 & $4.4^{* *}$ & 2.0 & $-2.7^{*}$ \\
\hline Cerebellar & & & & & & & & & & \\
\hline $\mathrm{Cul}^{\mathbf{T}}$ & $\mathrm{R}$ & & 1333 & 33 & -57 & -25 & 10.0 & 1.1 & $6.1^{* *}$ & $4.4^{* *}$ \\
\hline & $\mathrm{L}$ & & 1824 & -33 & -50 & -27 & 10.3 & 0.7 & $6.2 * *$ & $5.2 * *$ \\
\hline Dec & $\mathrm{R}$ & & 420 & 8 & -69 & -21 & 9.8 & 1.6 & $3.0^{*}$ & 1.3 \\
\hline & $\mathrm{L}$ & & 972 & -8 & -67 & -22 & 9.9 & $2.4^{*}$ & $3.4^{* *}$ & 1.1 \\
\hline Dec2 & $\mathrm{R}$ & & 59 & 0 & -60 & -15 & 9.5 & $3.4^{* *}$ & 1.3 & -0.6 \\
\hline
\end{tabular}


ucsd.edu/eeglab), a freely available open source toolbox running under Matlab (The Mathworks, Natick, MA). The removal of gradient and ballistocardiogram artifacts is described in detail in a previous publication using the same data set, reporting EEG signal quality and the auditory ERP N100 component in response to the frequent tone condition (Debener et al., 2007a). Briefly, fMRI gradient artifacts were removed using a local average artifact template procedure (Allen et al., 2000) as implemented in BrainVision Analyzer. Data were corrected relative to the MR volume gradient artifact onset which was indicated by a trigger received from the MR system and recorded with the EEG. A moving average width of $30 \mathrm{MR}$ volumes was used for gradient correction. Corrected EEG data were $0.3-40 \mathrm{~Hz}$ pass-band filtered, down-sampled to $250 \mathrm{~Hz}$ and exported to Matlab 7. For the removal of ballistocardiogram (BCG) artifacts, a combination of optimal basis set (OBS; Niazy et al., 2005) and ICA was found to provide the best ERP signal quality, and this approach was therefore used in the present study. OBS (implemented in the EEGLAB plug-in FMRIB 1.2, Niazy et al., 2005) provides a reliable heartbeat detection algorithm. The heartbeat events were used to generate and subtract a BCG template from the continuous data. Following correction for BCG artifacts using the OBS method, extended infomax ICA was performed on the concatenated OBS-corrected single-trial data. Independent components reflecting residual BCG artifacts were identified by correlating all IC topographies with the BCG artifact topography, and their contribution was removed by joint back-projection of the remaining independent components. For further details on using ICA in the context of ballistocardiogram removal, see Debener et al. (2007a). For the analysis of ERPs in response to the rare target and novel conditions, epochs from -200 to $800 \mathrm{~ms}$ were created and averaged, using a low pass filter of $15 \mathrm{~Hz}$ and a baseline removal from -150 to $0 \mathrm{~ms}$. Single-subject ERPs were rereferenced to the common average and exported to BESA (MEGIS Software $\mathrm{GmbH}$, Gräfelfing, Germany) for source analyses (see below). For statistical analyses with regard to novelty- and targetprocessing, we followed the approach used for the fMRI analyses and contrasted (1) novel sounds vs. rare tones (with targets and nontargets pooled) and (2) targets vs. nontargets (with novel sounds and rare tones pooled). Differences between the respective waveforms (as depicted in Fig. 4) were tested for significance at five midline electrodes (corresponding to $\mathrm{Fz}, \mathrm{FCz}, \mathrm{Cz}, \mathrm{CPz}$ and $\mathrm{Pz}$ ) using both a uncorrected level of significance of $\alpha=0.05$ as well as a Bonferroni-corrected level of significance, adjusted for the number of $t$-tests (250) performed at each electrode.

\section{Source modeling}

fMRI-informed source modeling was performed using the BrainVoyager/BESA interface. EEG and fMRI coordinate systems were matched by fitting the standard spherical coordinates of the 64 EEG channel layout to Talairach coordinates based on three fiducial landmarks (nasion and preauricular points). ERP sources were modeled as regional sources (RSs) to account for individual differences in cortical folding because RSs model the three-dimensional current vectors in a region of cortex regardless of the orientation of the cortical folds (Scherg and von Cramon, 1986). A four-shell spherical head model was applied to compute source activities.

RS locations were determined as follows: Of all the ROIs identified in the fixed-effects fMRI analyses (see above), only cortical ROIs with a cluster size larger than 1000 voxels were selected. In case of corresponding ROIs in the contralateral hemisphere with a smaller cluster size, the contralateral ROI was selected as well. To minimize "cross-talk" between RS (Bledowski et al., 2006), ROIs with less than $25 \mathrm{~mm}$ Euclidian distance between their centers of mass were considered as one RS located at the ROIs' mean center of mass. Bilateral RS locations were equalized by calculating their mean centers of mass. This resulted in twelve RSs comprising four bilateral RSs (precentral sulcus, inferior frontal gyrus/insula, superior temporal gyrus and intraparietal sulcus) and four singular medial RSs (frontomedial area, posterior cingulate, precuneus and cuneus). With two exceptions (posterior cingulate, cuneus), the identified RSs closely corresponded to those used by Bledowski et al. (2004b) in a related task. In addition to the sources described above, a right ventrolateral frontal RS was also included. Though this ROI was of slightly smaller size (928 voxels), its inclusion was guided by previous source modeling findings (Opitz et al., 1999) and is in agreement with the right-lateralized ventral fronto-parietal attention network as proposed by Corbetta and Shulman (2002). A corresponding RS was placed in the left hemisphere to achieve symmetry in the RS model, although no fMRI activation was observed there at the threshold used (see Results). The locations of the RS are given in Table 2.

The resulting discrete multiple source model was then applied to the single subject ERPs, and difference waveforms of the following conditions were derived: (1) novel sounds vs. rare tones, to examine differences in source activation more closely related to novelty-processing, i.e. the processing of novel sounds as compared to the processing of rare tones, regardless of whether the stimuli were targets or nontargets; and (2) targets vs. nontargets, to examine differences in source activation more closely related to target-processing, i.e. the processing of target as compared to nontarget stimuli, regardless of whether the stimuli were novel sounds or rare tones. To test for significance of differences between the respective conditions, we employed the same non-parametric bootstrapping procedure as used by Bledowski et al. (2004b, 2006). 95\% confidence limits were obtained for difference waveforms based on 5000 iterations and using a bootstrap bias-corrected and adjusted method (Efron and Tibshirani, 1993). Two conditions were considered significantly different

\footnotetext{
Notes to Table 1:

${ }^{1}$ ROI abbreviations: $\mathrm{MFG}=$ middle frontal gyrus; IFS=inferior frontal sulcus; PrCS=precentral sulcus; FrMed=medial frontal (including premotor and supplementary motor areas as well as superior portions of BA 32); IFG=inferior frontal gyrus; $\mathrm{STG}=$ superior temporal gyrus; IPS=intraparietal sulcus; $\mathrm{PrCu}=$ precuneus; $\mathrm{Cu}=$ cuneus; $\mathrm{LG}=$ lingual gyrus; $\mathrm{Caud}=$ nucleus caudatus $($ body); $\mathrm{Put}=$ putamen; $\mathrm{Th}=$ thalamus $($ ant $\mathrm{Nc}=$ anterior nucleus, $\mathrm{mdNc}=$ medial dorsal nucleus); Ins=insula; $\mathrm{Cul}=$ culmen (cerebellum); $\mathrm{Dec}=$ declive (cerebellum); prefixes to better characterize ROI-location: ant $=$ anterior; mid $=$ middle; post=posterior; inf=inferior; ${ }^{2}$ ROI definition based on fixed effects GLM; $t$-threshold for ROI selection: $t(15,568) \geq 9.2, P \leq 4.0 \times 10^{-20}$ (see the "'link to Materials and Methods section for details); $t$-values are average ROI $t$-values; ${ }^{3}$ contrast analysis based on random effects GLM; $t$-values with $d f=13$; ${ }^{*} P<0.05$ (two-tailed); ${ }^{* *} P<0.01$ (two-tailed); contrasts with $t>4.7$ are significant at $P<0.0004$ (two-tailed Bonferroni-corrected level of significance, corrected for number of ROIs [41] $\times$ contrasts [3]); ${ }^{\mathrm{N}}$ novelty-related activation, ${ }^{\mathrm{T}}$ target-related activation (see Figs. 1 and 2 ).
} 
A
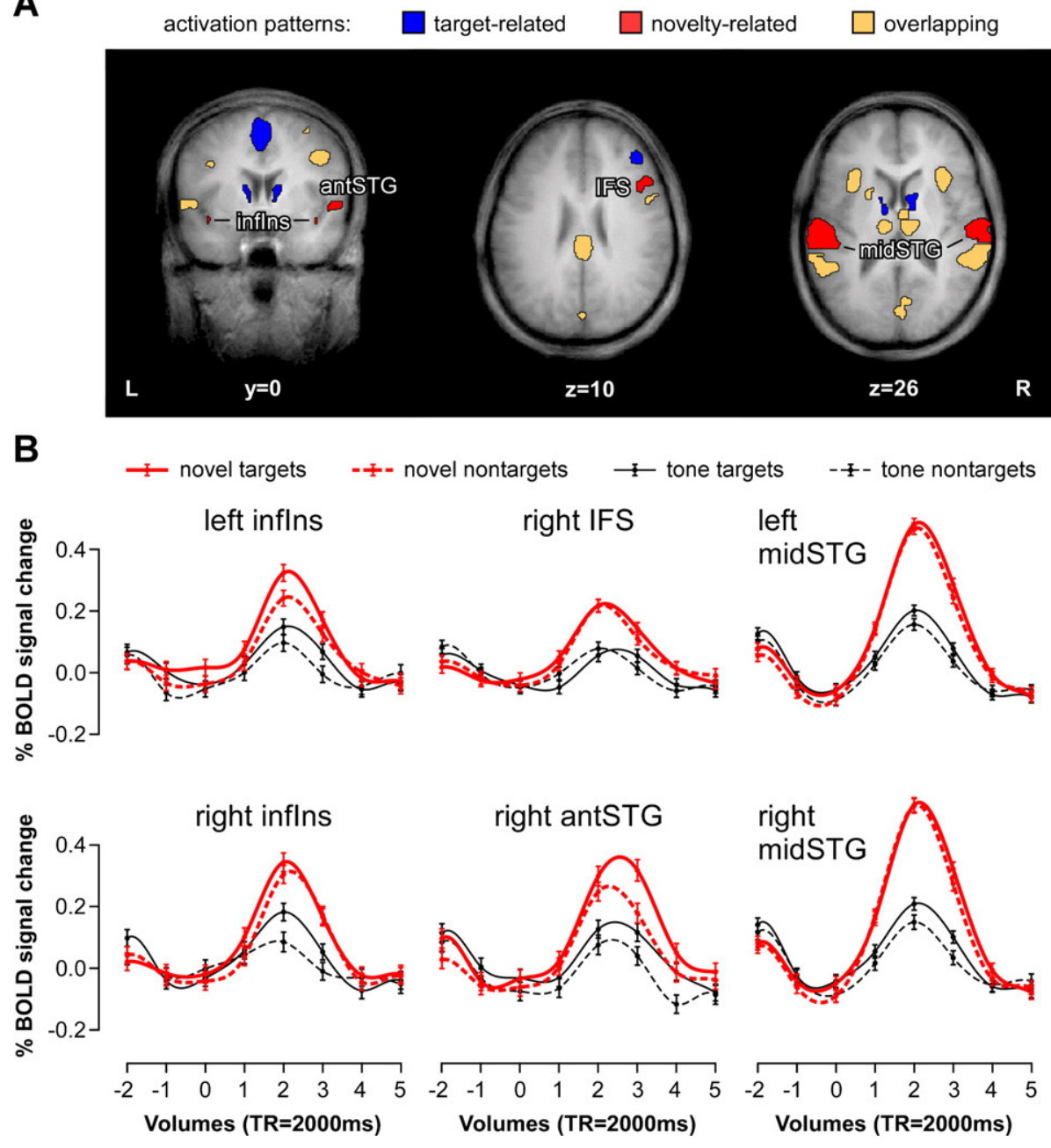

Fig. 1. fMRI results: Regions of interest (ROI) with distinct activation patterns related to novelty-processing. (A) Red ROIs indicate novelty-related activation patterns, blue ROIs correspond to target-related activation (cf. Table 1 and Fig. 2); yellow ROIs correspond to overlapping activation, i.e. activation by both novels and targets. ROIs are superimposed over the averaged brains of all subjects. (B) Average event-related BOLD time courses ( $z$-values \pm standard errors of means, spline-interpolated for illustration purposes only) for novel sounds (thick/red lines), rare tones (thin/black lines), targets (solid lines) and nontargets (dashed lines). ROI abbreviations: infIns=inferior insula; IFS=inferior frontal sulcus; antSTG/midSTG=anterior/middle part of superior temporal gyrus.

if the confidence interval of the difference source waveform did not include zero. Procedures like this inflate the number of statistical tests but reveal information about the temporal evolution of significant condition effects and have been successfully used elsewhere (Bledowski et al., 2004b; Bledowski et al., 2006; Hine and Debener, 2007).

\section{Results}

\section{Behavioral results}

Participants performed well in counting the targets. The overall counting error rate across conditions (count rare tones, count novel sounds) and runs (two runs each) was $4 \%$ with a range of $0-8 \%$. A repeated measures analysis of variance with condition $\times$ run as within-subjects factors showed neither significant differences in error rates between conditions or runs nor a significant condition $\times$ run interaction effect (all $P \geq 0.35$ ).

\section{fMRI results}

Table 1 summarizes the anatomical areas and the Talairach coordinates of brain regions that showed significant activation in any of the four conditions of the task compared to baseline (fixed effects GLM: all $t(15,568) \geq 9.2$, all $\left.P_{\text {Bonf }} \leq 1.9 \times 10^{-15}\right)$ and also shows the results of subsequent contrast analyses based on these ROIs using a random effects (RFX) GLM (Figs. 1 and 2).

Six ROIs exhibited a distinct activation pattern related to novelty-processing (Fig. 1), i.e. significantly higher activation for novel sounds compared to rare tones, regardless of whether they were targets or nontargets; no significant target-nontarget difference; and significantly lower activation for rare targets than for novel nontargets. These regions comprised right inferior frontal sulcus (IFS) and anterior superior temporal gyrus (antSTG) and bilateral middle superior temporal gyrus (midSTG) and inferior insula (infIns). Event-related averaging (Fig. 1B) revealed that especially right IFS and bilateral midSTG unambiguously 
A

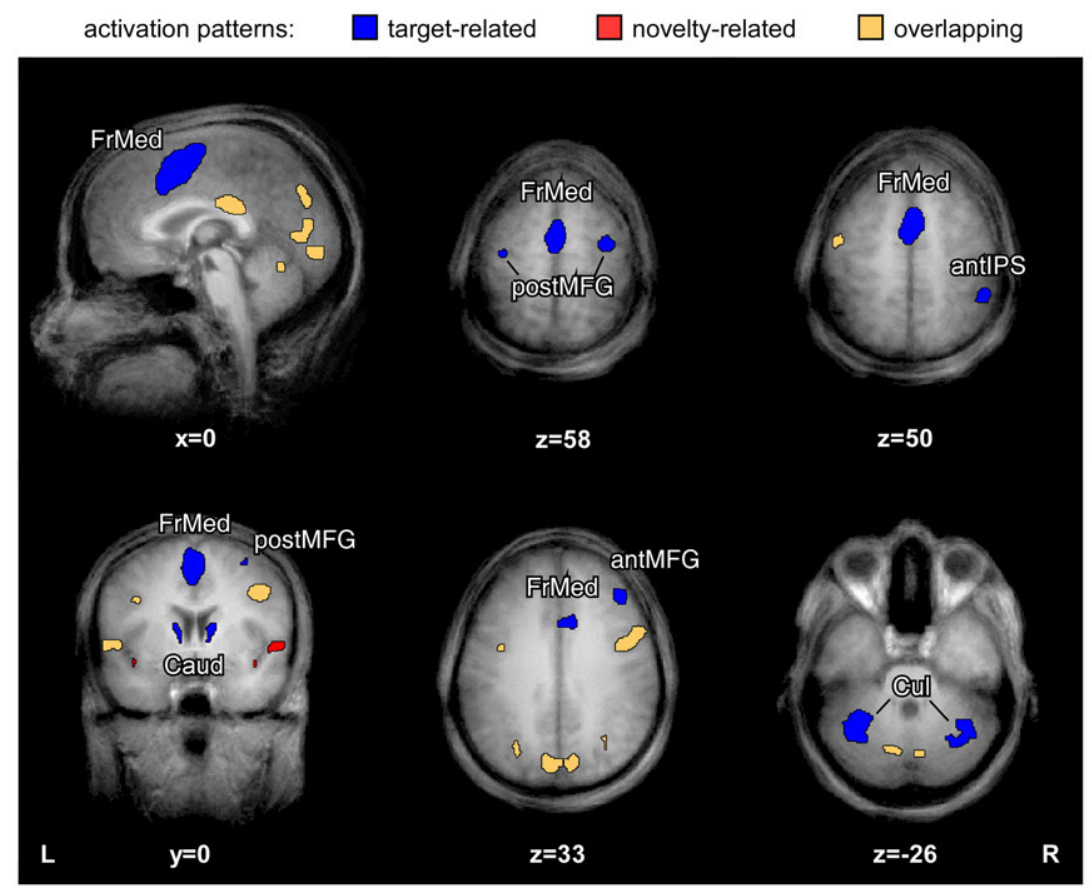

B I novel targets - - - novel nontargets $\quad I$ tone targets $\quad-\mathbf{\Psi}$ - tone nontargets

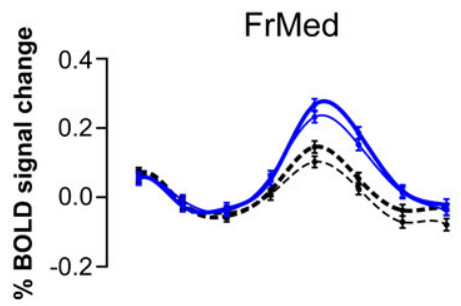

right antMFG

right antIPS

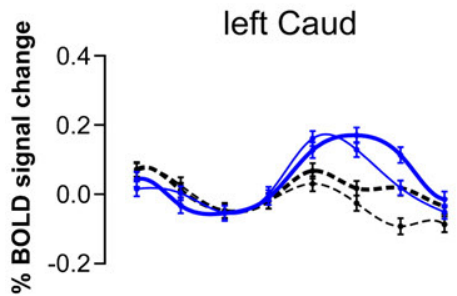

left postMFG
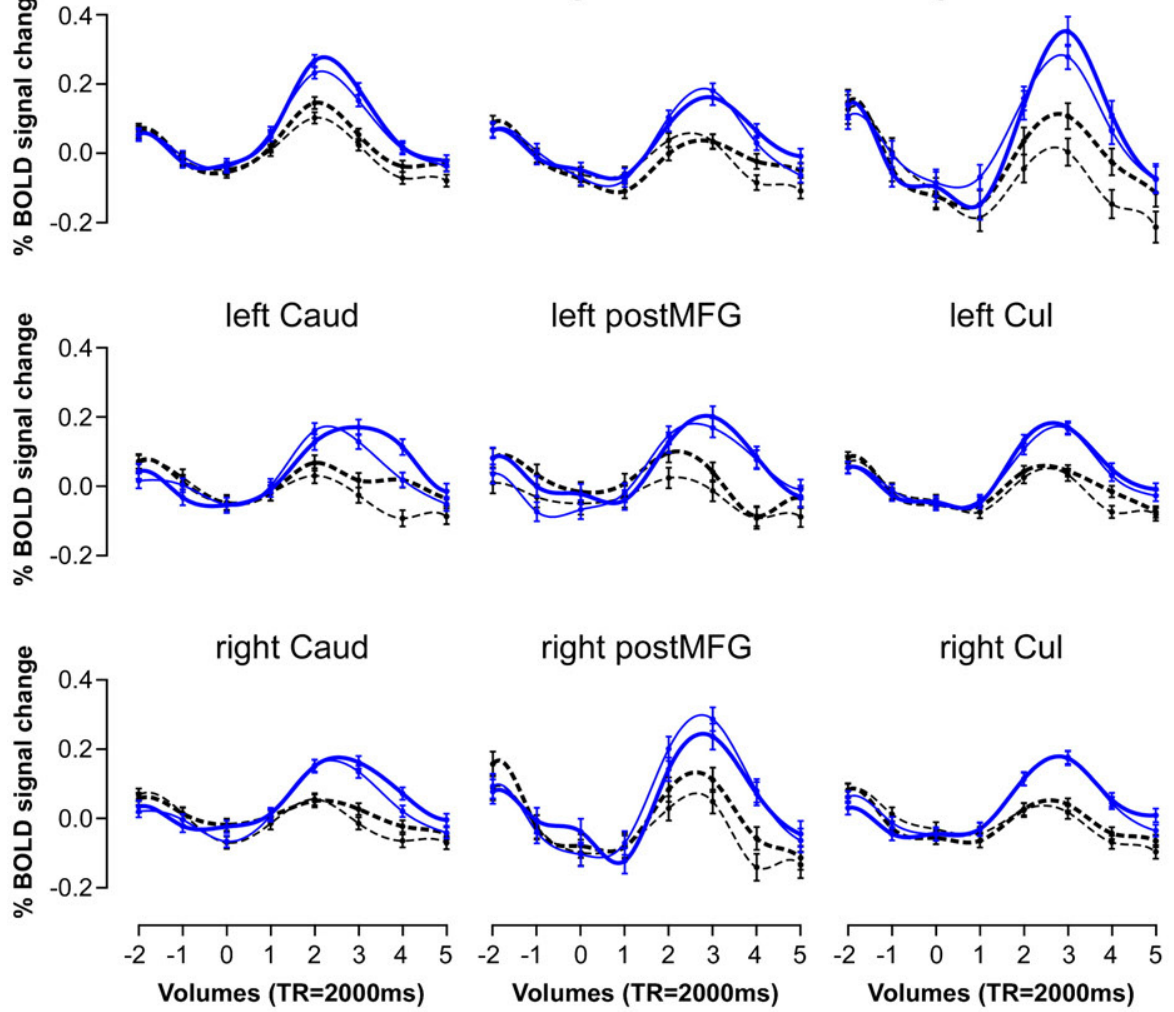

right postMFG

right Cul
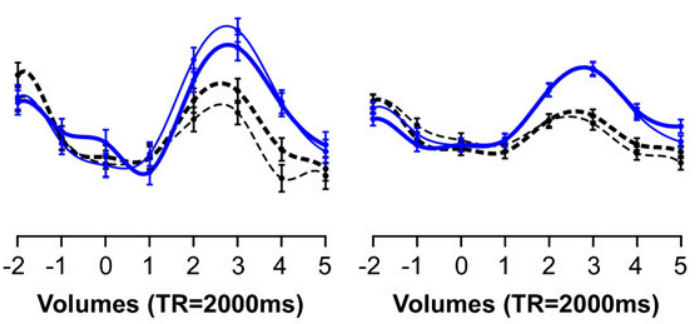

Fig. 2. fMRI results: Regions of interest (ROI) with distinct activation patterns related to target-processing. (A) Blue ROIs indicate target-related activation patterns, red ROIs correspond to novelty-related activation (cf. Table 1 and Fig. 1), and yellow ROIs indicate overlapping activation, i.e. activation by both novels and targets. ROIs are superimposed over the averaged brains of all subjects. (B) Average event-related BOLD time courses ( $z$-values \pm standard errors of means, spline-interpolated for illustration purposes only) for targets (solid/blue lines), nontargets (dashed/black lines), novel sounds (thick lines) and rare tones (thin lines). ROI abbreviations: FrMed=medial frontal; Caud = nucleus caudatus (body); ant/postMFG = anterior/posterior middle frontal gyrus; antIPS = anterior intraparietal sulcus; $\mathrm{Cul}=$ culmen (cerebellum). 
novel sounds
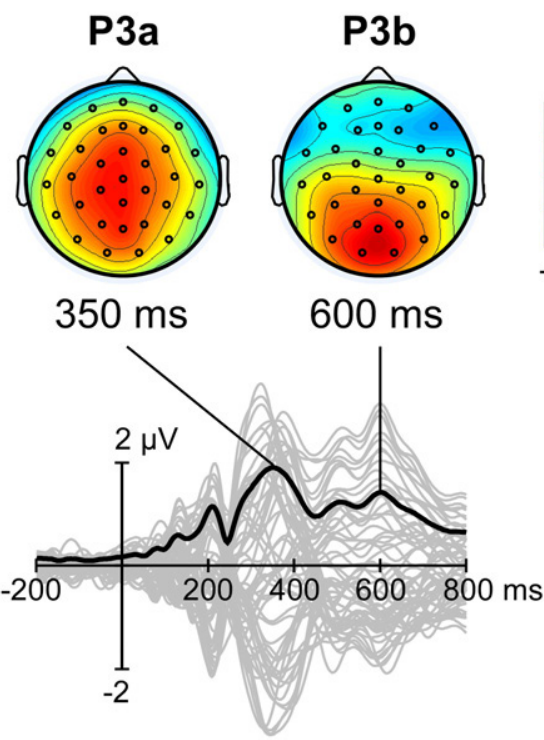

targets
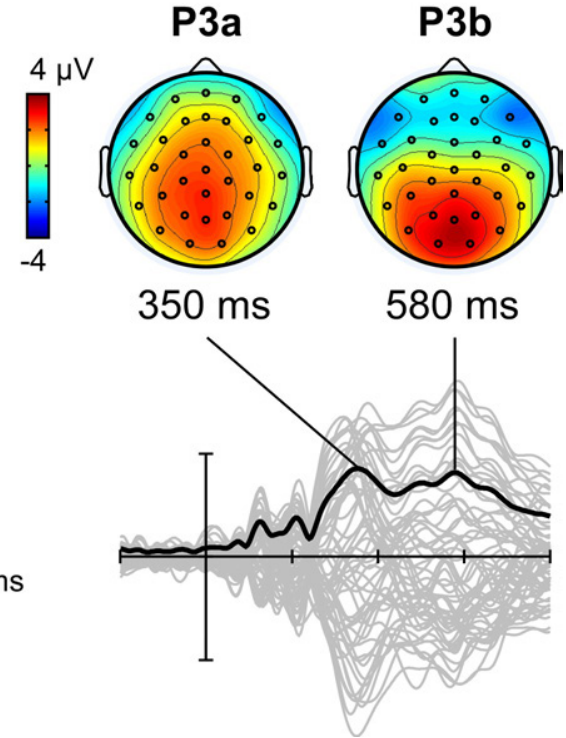

Fig. 3. ERP results: Grand average $(N=14)$ butterfly plots (gray lines) and mean global field power (black lines) for novels (left; targets and nontargets combined) and targets (right; novel sound and rare tone targets combined). Topographical voltage maps at novelty P3/P3a and P3b peak latencies are shown (top view, 34 of 61 electrodes shown).

exhibited novelty-related activation. To examine whether the lack of a left counterpart to the right IFS ROI was due to the comparably stringent $t$-threshold used to identify clusters of activation, i.e. $t(15,568)=9.2$, the $t$-threshold was lowered, and at $t(15,568)=8.0, P_{\text {Bonf }}=6.2 \times 10^{-11}$, a left IFS cluster was observed (cluster size: 112 voxels; Talairach coordinates: $x=-41, y=23$, $z=28$ ). However, inspection of event-related averages and RFX contrast analyses did not identify this ROI as novelty-related. Moreover, laterality tests, performed by entering the individual beta-weights of the RFX analyses of both ROIs into a repeated measures ANOVA with stimulus type (novel sounds vs. rare tones), target instruction (target vs. nontarget) and hemisphere (right vs. left) as within-subjects factors, indicated that there was significantly higher left hemispheric IFS activation in the novel sounds condition regardless of target instruction (interaction effect stimulus type $\times$ hemisphere, $F(1,13)=8.28, P=0.013$; all other effects involving hemisphere $P>0.05$ ).

Eight ROIs were found to exhibit a distinct activation pattern related to target-processing (Fig. 2A), i.e. significantly higher activation for targets compared to nontargets, regardless of whether they were novel sounds or rare tones; no significant differences between novels and rares; and significantly higher activation for rare targets compared to novel nontargets. These regions were right anterior middle frontal gyrus (antMFG), widespread bilateral frontomedial gyrus (FrMed, including premotor and supplementary motor regions as well as superior portions of BA 32), right posterior middle frontal gyrus (postMFG), anterior intraparietal sulcus (antIPS), right insula (Ins), right caudate (Caud) and bilateral culmen (cerebellum, Cul). Inspection of the remaining contrasts and the event-related averages, however, indicated that the right insula showed a trend towards higher activation for novels compared to rares $(t(13)=2.0, P=0.069)$, and the event-related average also did not show a clear-cut target-related activation pattern. On the other hand, visual inspection of the event-related averages resulted in the identification of two additional target-related ROIs that would have been excluded if considering the contrast-based criteria only. These were left postMFG, where the rare targets vs. novel nontargets contrast only slightly missed significance $(t(13)=2.0, P=0.064)$, and left caudate, where the novels vs. rares contrast was significant $(t(13)=3.6$, $P=0.003)$. In both cases, however, inspection of the event-related average justified the characterization of these ROIs as target-related. Fig. 2B shows the event-related averages of the final set of nine ROIs distinctly related to target-processing. To examine, whether lefthemispheric counterparts to the two unilateral target-related ROIs antMFG and antIPS could be observed at less stringent $t$-thresholds than the one applied in the initial analyses, i.e. $t(15,568)=9.2$ for frontal areas and $t(15,568)=10.8$ for parietal regions, the $t$-threshold was lowered. Left-hemispheric antMFG activation was observable at $t(15,568)=7.5$, $P_{\text {Bonf }}=3.1 \times 10^{-9}$ (50 voxels; $\left.x=-31, y=38, z=28\right)$, and left antIPS activation was observable at $t(15,568)=9.8, P_{\mathrm{Bonf}}=6.1 \times 10^{-18}$ (cluster size: 58 voxels; Talairach coordinates: $x=-49, y=-41, z=42$ ). In both cases, RFX contrast analyses did not identify these ROIs as targetrelated; however inspection of the event-related averages to some extent indicated higher activation for targets than for nontargets, and laterality tests for these ROIs did not reveal main effects of hemisphere or interactions of hemisphere with stimulus type or target instruction (repeated measures ANOVA, all $P>0.05$ ), i.e. there were no differences in activation for these ROIs in both hemispheres. Hence, target-related activation cannot fully be ruled out for the left antMFG and antIPS ROI.

\section{ERP results}

Fig. 3 shows grand average butterfly plots of the OBS-ICAcorrected ERPs as well as the global field power for novels (targets and nontargets pooled) and targets (novel sound and rare tone targets pooled). The topographical voltage maps at novelty P3/P3a and P3b peak latencies are shown as well. The global field power waveforms clearly indicate the presence of novelty P3/P3a and P3b 
novel sounds vs. rare tones

(targets and nontargets combined)
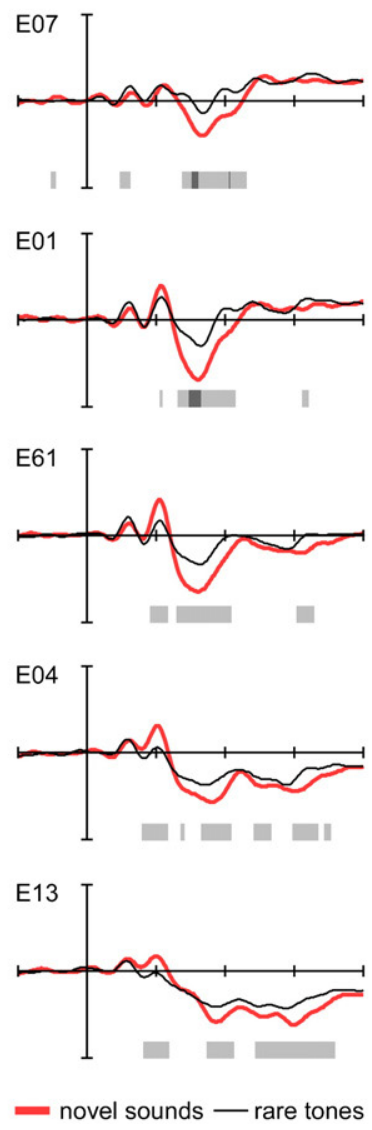

\section{targets vs. nontargets}

(novel sounds and rare tones combined)
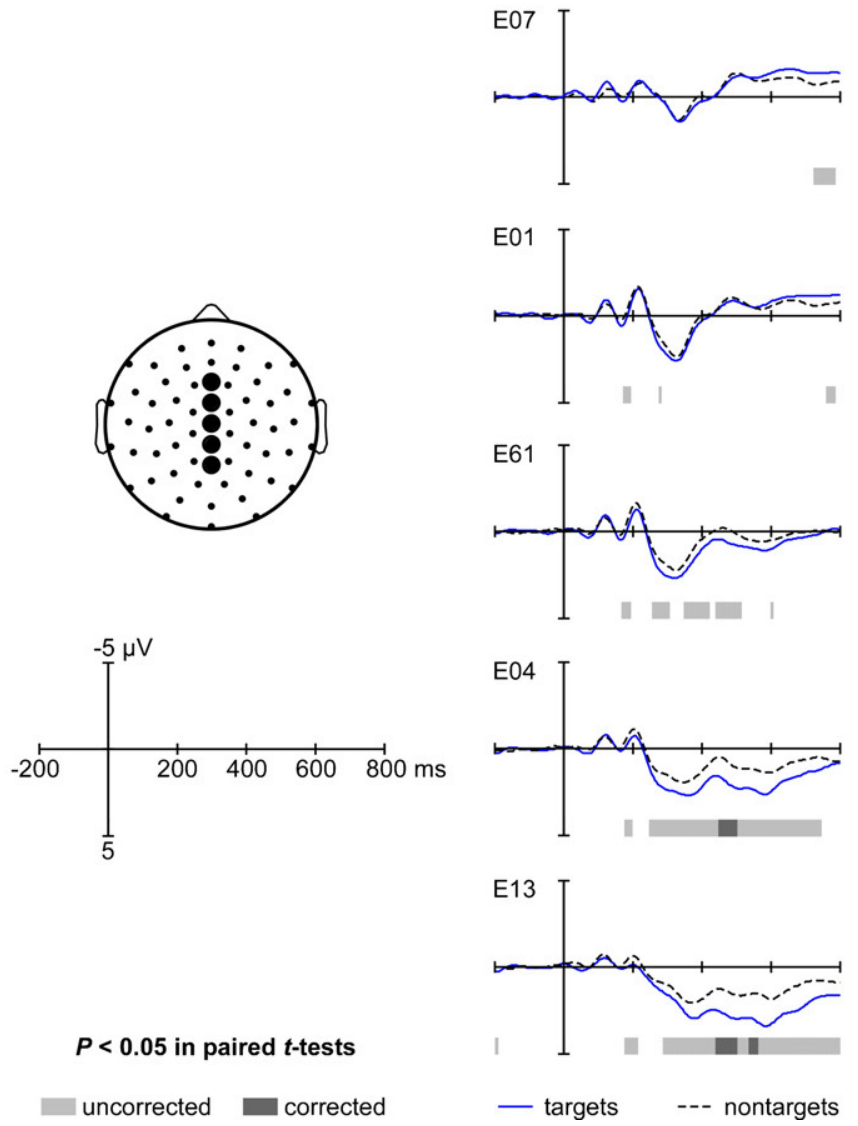

Fig. 4. ERP results: Grand average $(N=14)$ ERPs at selected midline electrodes (see headplot), contrasting novel sounds and rare tones (targets and nontargets combined, left panel) and targets and nontargets (novel sounds and rare tones combined, right panel). Gray-shaded bars at the bottom of each graph indicate time intervals with significant differences between the waveforms as determined by paired $t$-tests for each data point; light gray bars: $P<0.05$ (uncorrected), dark gray bars: $P<0.05$ (corrected for multiple testing, Bonferroni correction factor: 250 ).

peaks. The corresponding maps show the expected topographical pattern of a central distribution of the novelty P3/P3a peaking at $350 \mathrm{~ms}$ (Fig. 3, upper left panel). Targets also evoked a P3a peaking at $350 \mathrm{~ms}$ with a similar, slightly more posterior distribution (Fig. 3, upper right panel). The P3b showed the expected pattern of a posterior voltage distribution for both novel and target conditions, with the target $\mathrm{P} 3 \mathrm{~b}$ peaking slightly earlier $(580 \mathrm{~ms})$ than the novelty P3b (600 ms).

Fig. 4 shows the grand average ERPs at selected midline electrodes, contrasting novel sounds and rare tones (targets and nontargets pooled, Fig. 4, left panel), and targets and nontargets (novel sounds and rare tones pooled, Fig. 4, right panel). Descriptively, all stimuli of interest evoked a more or less pronounced novelty $\mathrm{P} 3 / \mathrm{P} 3 \mathrm{a}$ and $\mathrm{P} 3 \mathrm{~b}$, with a higher novelty $\mathrm{P} 3 / \mathrm{P} 3 \mathrm{a}$ for novel sounds than for rare tones and a higher $\mathrm{P} 3 \mathrm{~b}$ for targets than for nontargets. Fig. 4 also shows the results of paired $t$-tests of the respective individual waveforms. At the Bonferroni-corrected level of significance (adjusted for the number of $t$-tests per electrode site, i.e. 250), the novel sounds vs. rare tones contrast (Fig. 4, left panel) was significant only at the frontocentral sites E07 and E01 (corresponding to $\mathrm{Fz}$ and $\mathrm{FCz}$; both $P<0.05$, corrected), thereby confirming the expected frontocentral effect related to novelty-processing. It has to be noted, however, that at the conventional, uncorrected level of significance of $\alpha=0.05$, higher amplitudes for novel sounds were also observable in both the N2 time range around $(200 \mathrm{~ms})$ and the $\mathrm{P} 3 \mathrm{~b}$ time range (around $600 \mathrm{~ms}$; all $P<0.05$, uncorrected, at all but the frontal site E07).

The target vs. nontarget contrast (Fig. 4, right panel) was significant at the Bonferroni-adjusted level only for the $\mathrm{P} 3 \mathrm{~b}$ at the posterior electrodes E04 and E13 (corresponding to $\mathrm{CPz}$ and $\mathrm{Pz}$; $P<0.05$, corrected), confirming the expected parietal effect related to target-processing. Again, additional significant effects emerged when using the conventional level of significance: higher amplitudes for targets were observed also in the novelty $\mathrm{P} 3 / \mathrm{P} 3 \mathrm{a}$ time range $(P<0.05$, uncorrected, at centroparietal sites $)$ as well as for a late frontal negativity $(P<0.05$, uncorrected, at frontocentral sites), and higher amplitudes for nontargets were found in the N2 time range $(P<0.05$, uncorrected, at centroparietal sites). Taken together, the overall picture is in line with our expectations concerning condition- and stimulus-specific differences in P3a and P3b amplitudes, but also point to additional condition- and 
Table 2

fMRI-informed source modeling: regional sources (RS) and corresponding Talairach coordinates

\begin{tabular}{|c|c|c|c|c|c|}
\hline \multirow[t]{2}{*}{ RS name } & \multirow[t]{2}{*}{$\begin{array}{l}\text { RS } \\
\text { abbreviation }\end{array}$} & \multirow[t]{2}{*}{ Side } & \multicolumn{3}{|c|}{$\begin{array}{l}\text { Talairach } \\
\text { coordinates }\end{array}$} \\
\hline & & & $x$ & $y$ & $z$ \\
\hline \multicolumn{6}{|l|}{ Bilateral RS } \\
\hline \multirow[t]{2}{*}{ Ventrolateral frontal } & \multirow[t]{2}{*}{$\mathrm{vlFr}$} & $\mathrm{R}$ & 38 & 27 & 32 \\
\hline & & $\mathrm{L}$ & -38 & 27 & 32 \\
\hline \multirow[t]{2}{*}{ Precentral sulcus } & \multirow[t]{2}{*}{ PrCs } & $\mathrm{R}$ & 38 & 2 & 36 \\
\hline & & $\mathrm{L}$ & -42 & 1 & 33 \\
\hline \multirow[t]{2}{*}{ Inferior frontal/insular } & \multirow[t]{2}{*}{ ifIns } & $\mathrm{R}$ & 37 & 18 & 12 \\
\hline & & $\mathrm{L}$ & -40 & 17 & 9 \\
\hline \multirow[t]{2}{*}{ Superior temporal gyrus } & \multirow[t]{2}{*}{ STG } & $\mathrm{R}$ & 53 & -30 & 16 \\
\hline & & $\mathrm{L}$ & -55 & -31 & 12 \\
\hline \multirow[t]{2}{*}{ Intraparietal sulcus } & \multirow[t]{2}{*}{ IPS } & $\mathrm{R}$ & 28 & -60 & 38 \\
\hline & & $\mathrm{L}$ & -31 & -61 & 35 \\
\hline \multicolumn{6}{|l|}{ Medial RS } \\
\hline Frontomedial & \multicolumn{2}{|l|}{ FrMed } & -2 & 3 & 48 \\
\hline Posterior cingulate & \multicolumn{2}{|l|}{ postCing } & -1 & -28 & 27 \\
\hline Precuneus & \multicolumn{2}{|l|}{$\mathrm{PrCu}$} & -1 & -73 & 33 \\
\hline Cuneus & \multicolumn{2}{|l|}{$\mathrm{Cu}$} & -1 & -72 & 10 \\
\hline
\end{tabular}

stimulus-specific differences which have to be taken into account in the interpretation of the source modeling results which are summarized in the following.

\section{Source modeling}

As described in detail in the Materials and methods section, fMRI-informed source modeling yielded 14 regional sources (RSs) located bilaterally in ventrolateral frontal and inferior frontal/ insular regions as well as in precentral sulcus, superior temporal gyrus and intraparietal sulcus and medially in frontomedial and posterior cingulate regions as well as in precuneus and cuneus. Table 2 gives the RS coordinates (see also Figs. 5 and 6 for an overview).

To examine source activation related to novelty-processing, the source model was applied to the single subject ERPs of the novel sounds condition and the rare tones condition, with targets and nontargets combined in each condition. The mean residual variance (RV) for the novel sounds condition was $14.09 \%$ (standard deviation $\mathrm{SD}=7.81 \%$ ), for the rare tones condition, the mean $\mathrm{RV}$ was $15.39 \%(\mathrm{SD}=6.08 \%)$. Fig. 5 displays the mean root mean square source activity waveforms for each RS as well as the difference waves with their $95 \%$ confidence interval as determined by bootstrapping. Here, the interval of interest was the novelty P3 time range (around $350 \mathrm{~ms}$ ). Descriptively, prominent peaks of the difference wave in this window could be observed for all frontal and temporal RSs, which were statistically significant for the bilateral ventrolateral frontal and the frontomedial RSs, left inferior frontal/insular RSs and bilateral superior temporal RSs. Significant novelty-related source activation in the novelty P3 time window was also observed for posterior cingulate as well as for the parietal and occipital RSs, although descriptively, these RSs' activations showed only minor deviations from zero in this time frame. Interestingly, nearly all RSs showed a second peak in the P3b time window (around $600 \mathrm{~ms}$ ). Furthermore, a significant noveltyrelated difference in N2 time range (around $200 \mathrm{~ms}$ ) emerged for the precentral sulcus RSs.
To examine source activation related to target-processing, the source model was applied to the single subject ERPs of the target condition (mean $\mathrm{RV}=13.68 \%, \mathrm{SD}=7.24$ ) and the nontarget condition (mean $\mathrm{RV}=15.97, S D=7.42$ ), with novel sounds and rare tones combined in each condition. Fig. 6 displays the source activity waveforms of each RS as well as the difference waves with their $95 \%$ confidence interval as determined by bootstrapping. Here, the main interval of interest was in the P3b latency range. All RSs showed a more or less pronounced contribution at about 500 $600 \mathrm{~ms}$, with significant target-related source activation emerging for all RSs except for right ventrolateral, inferior frontal/insular and precentral sulcus RSs as well as bilateral superior temporal gyrus RSs. In the earlier novelty P3/Pa interval, significant target-related source activation was observed for left inferior frontal/insular and superior temporal RSs, for bilateral intraparietal sulcus and for the medial precuneus and cuneus RSs.

\section{Discussion}

The present study provides further insights into the neural correlates of top-down target-processing and bottom-up noveltyprocessing. Specifically, we disentangled brain regions distinctly related to novelty- and target-processing from those regions being similarly involved in either of the two attentional processes. Furthermore, by means of simultaneous EEG and fMRI recordings, it was explored how fMRI activation contributed to the wellknown ERP signatures of novelty- and target-processing, that is, the novelty P3 and the P3b ERP components.

\section{Overlapping activation}

The present fMRI analyses revealed 41 ROIs to be activated in either one of the conditions of the auditory novelty oddball paradigm. These ROIs comprised widespread cortical and subcortical regions, and with a less stringent $t$-threshold, even more ROIs would have been identified. This general finding of a large number of brain regions being involved in both bottom-up-and topdown processing conforms with earlier studies employing visual oddball paradigms (e.g. Bledowski et al., 2004a; Gur et al., 2007; Kiehl et al., 2001) and can also be expected theoretically: In their neuroanatomical model of top-down-and bottom-up-driven attentional control, Corbetta and Shulman (2002) proposed a dorsal and a ventral frontoparietal network, with the former being involved in top-down-driven attention, but also in stimulus detection, and with the latter being implicated in the detection of salient and unexpected and potentially behaviorally relevant stimuli. The dorsal network comprises intraparietal and superior frontal regions, namely the frontal eye fields, while the ventral network includes temporoparietal and inferior frontal cortex. Also in our study, we found activation in these areas (dorsal network: posterior intraparietal sulcus and the precentral sulcus ROIs; ventral network: posterior temporal gyrus and inferior frontal gyrus ROIs; see Table 1) being similarly related to target- and novelty-processing. Hence, both networks seem to be involved in salience processing, with stimulus salience being determined by their rare occurrence, their task relevance, or their novelty and complexity.

To some extent, this is also agreement with the "adaptive reflexive processing" model by Kiehl et al. (2005), who propose "that the mammalian brain has evolved to adopt a strategy of engaging distributed neuronal systems when processing salient stimuli despite the low probability that many of these brain regions 

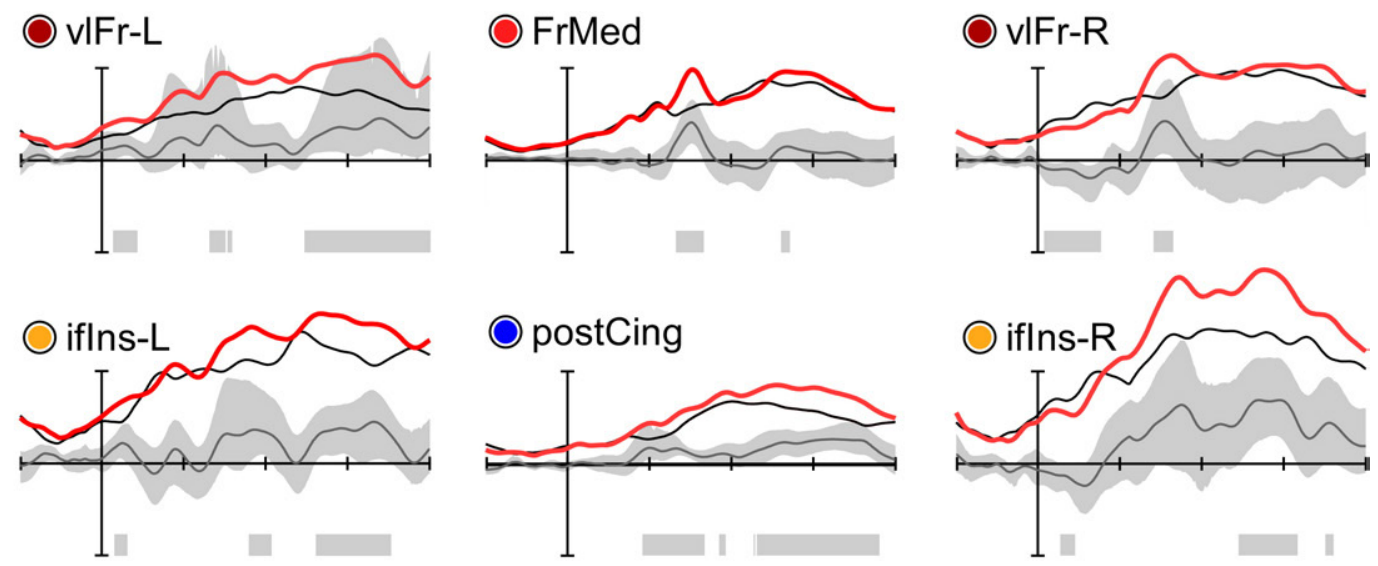

OPrCS-L
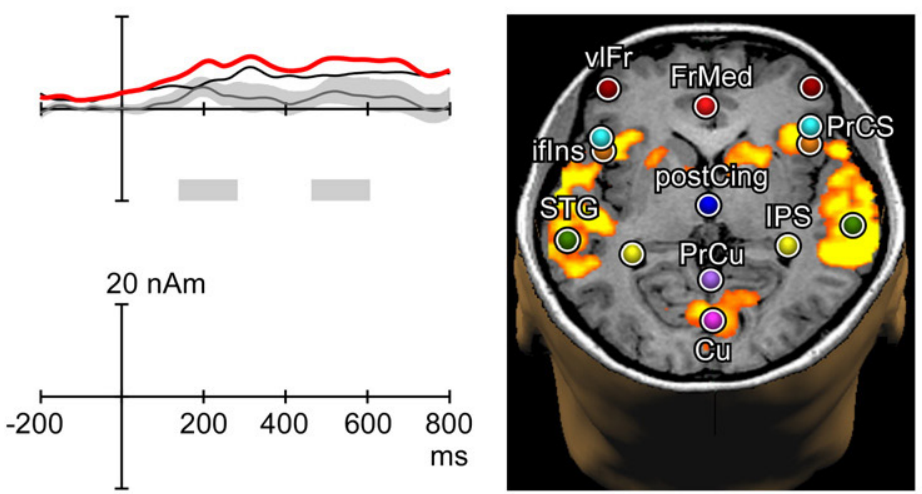

OPrCS-R
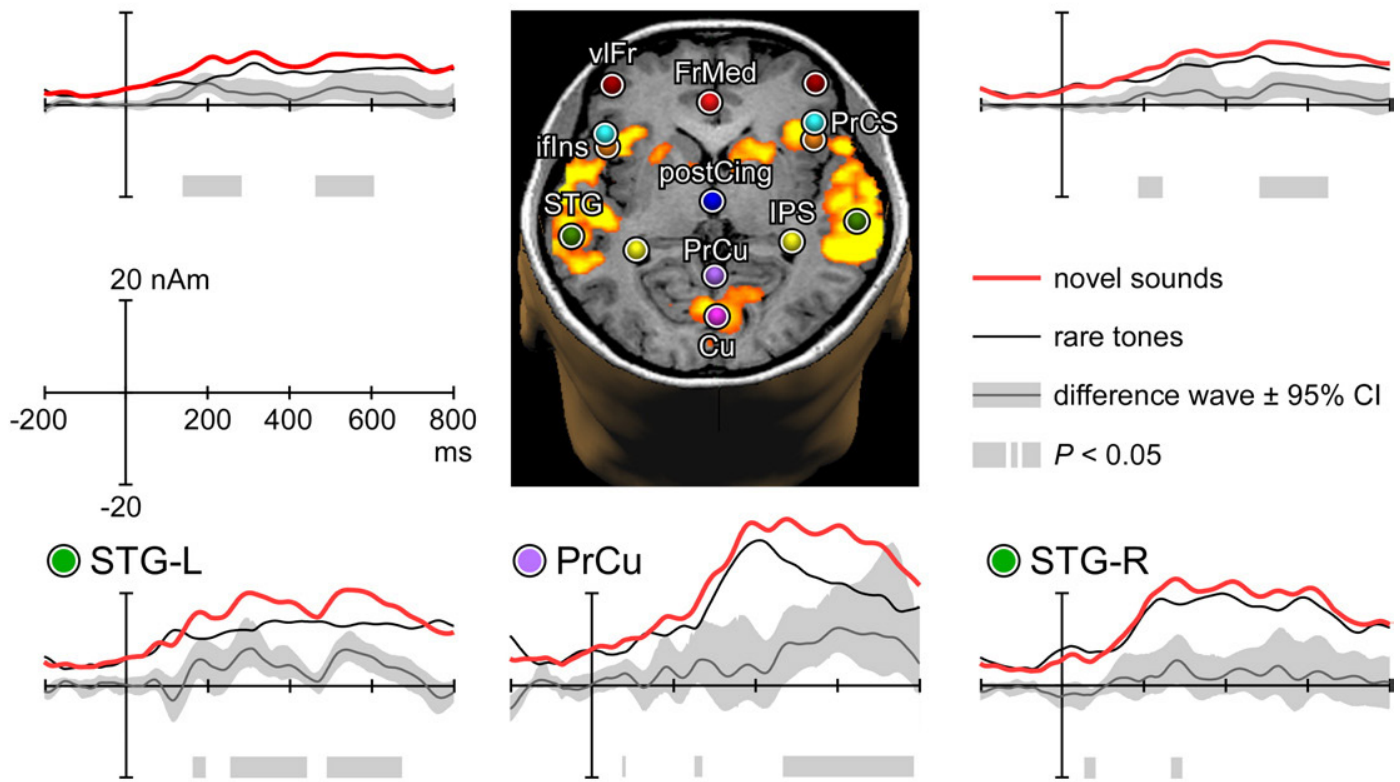

novel sounds

- rare tones

- difference wave $\pm 95 \% \mathrm{Cl}$

ㄱIII $P<0.05$
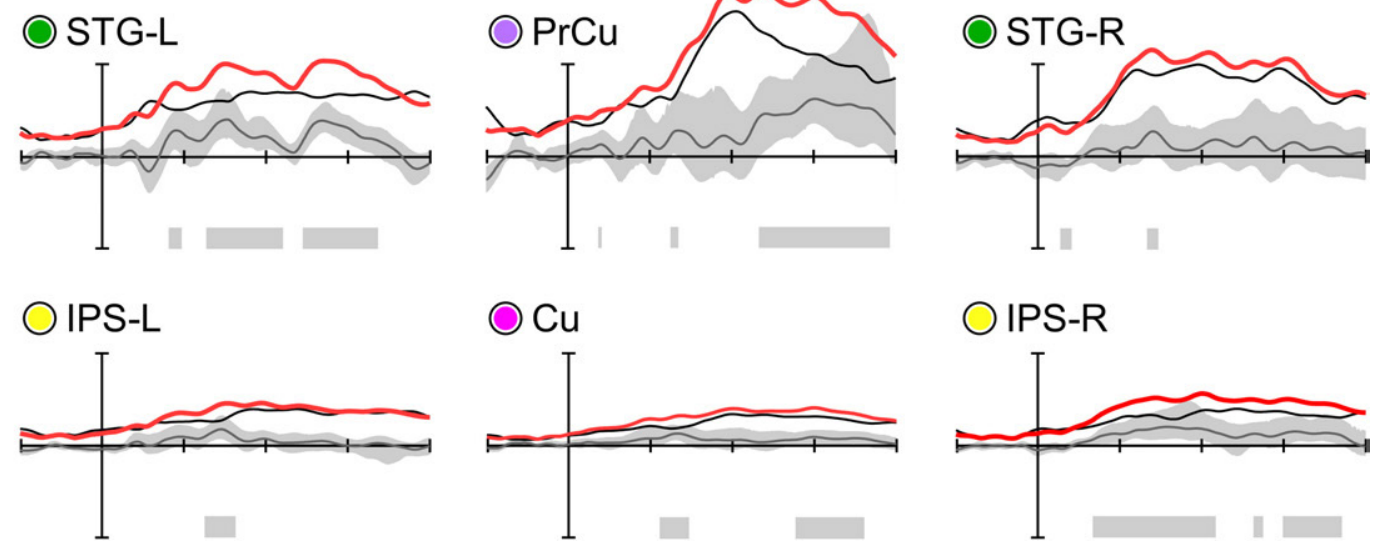

Fig. 5. Source modeling results: Novelty-related source activations. Thick/red lines indicate novel sounds (targets and nontargets combined), thin/black lines indicate tones (targets and nontargets combined). The gray line depicts the difference wave with its $95 \%$ confidence interval as determined by bootstrapping. Gray bars at the bottom of each graph indicate time intervals where the respective sources had significantly higher power in the novelty condition than in the tone condition. Source abbreviations: $\mathrm{vlFr}=$ ventrolateral frontal; iflns=inferior frontal/insular; $\operatorname{PrCS}=$ precentral sulcus; STG=superior temporal gyrus; IPS = intraparietal sulcus; $\mathrm{FrMed}=$ medial frontal; postCing = posterior cingulate; $\mathrm{PrCu}=$ precuneus; $\mathrm{Cu}=$ cuneus .

are required for successful task performance (Kiehl et al., 2005, p. 899)". Apart from the activation dorsal and ventral frontoparietal activation discussed above in the context of salience processing, the occipital activation observed in the present investigation of auditory processing provides another example for such an "adaptive reflexive" response as it may indicate that the occurrence of unexpected sounds signals the necessity to activate visual areas in order to be able to rapidly identify the source of an unexpected and potentially behaviorally significant sound.

Despite the considerable overlap of the regions involved in novelty- and target-processing, our study also revealed a number of brain regions more distinctly activated by either process. 

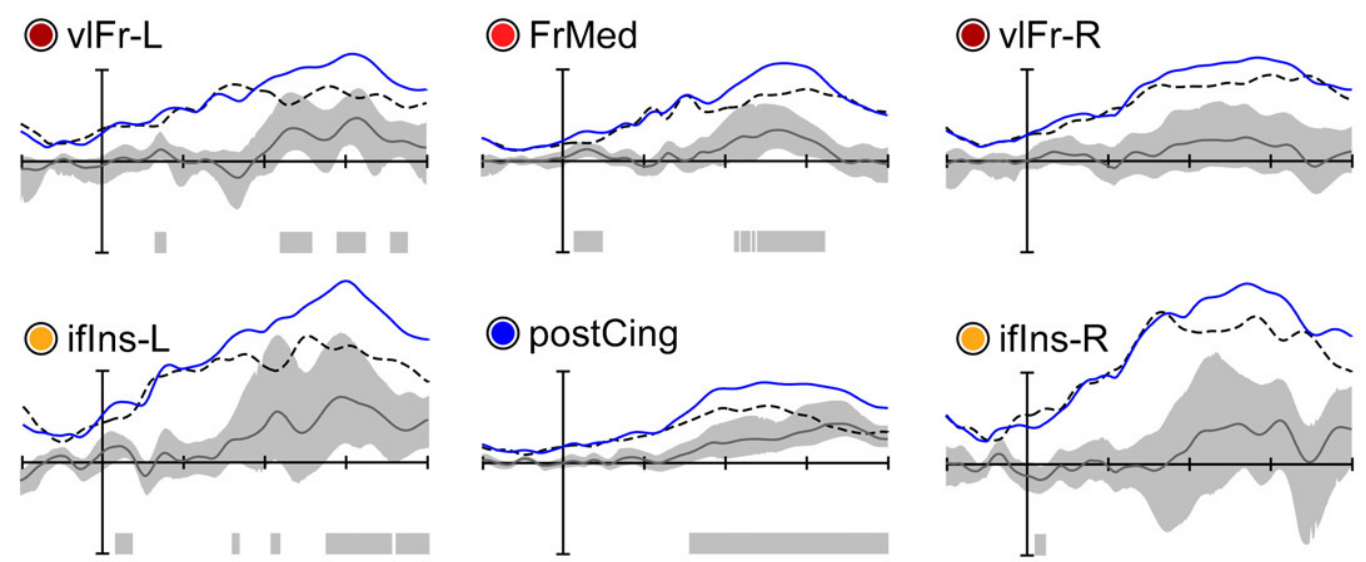

OPrCS-L
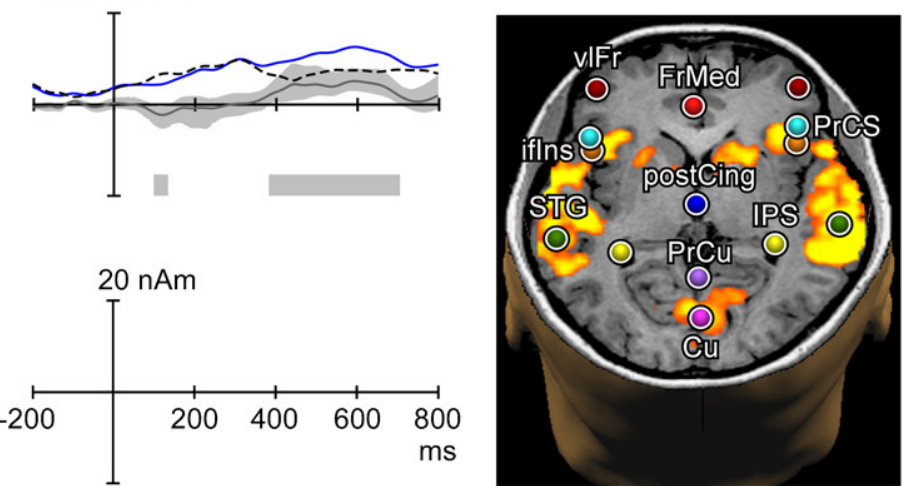

OPrCS-R
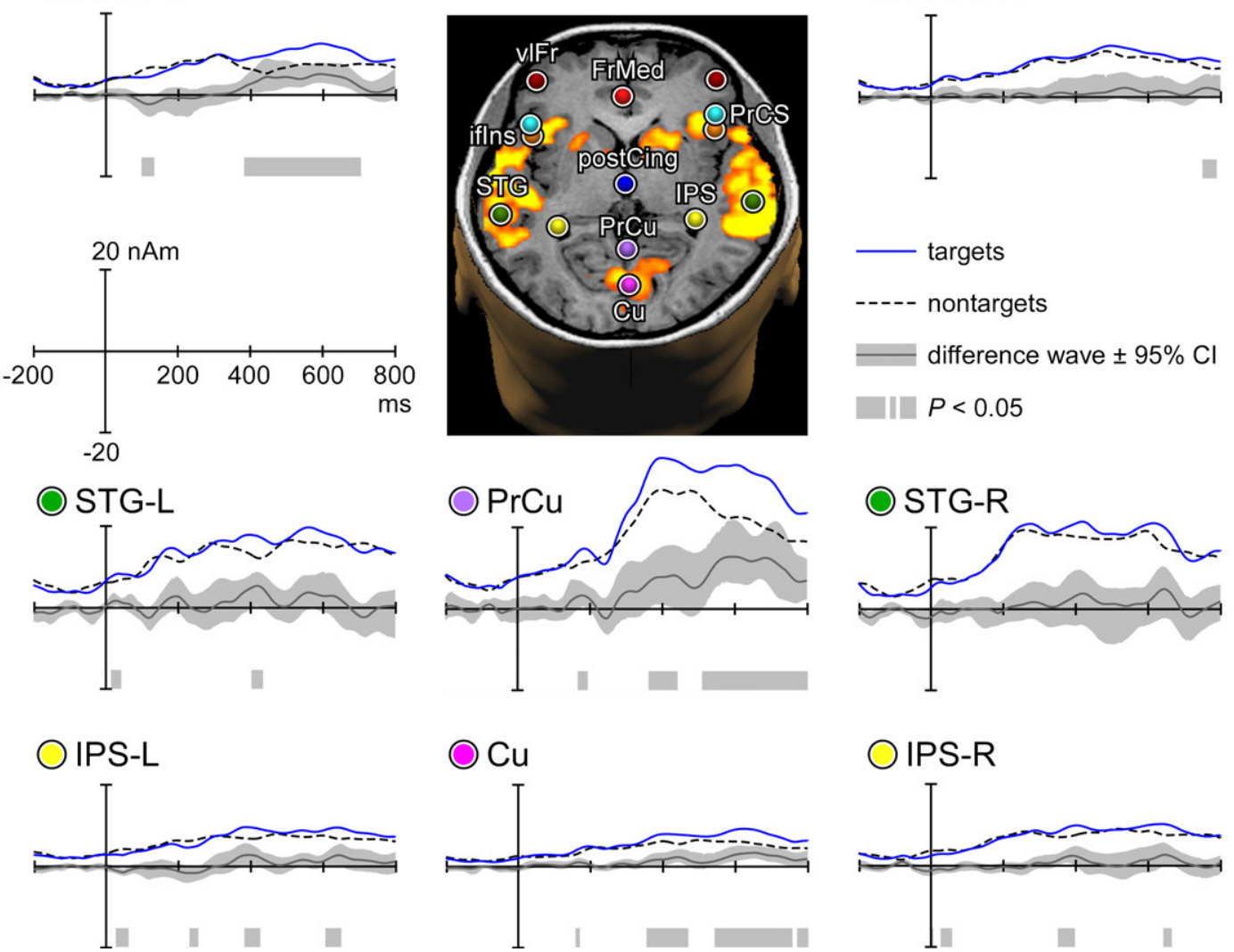

Fig. 6. Source modeling results: Target-related source activations. Solid/blue lines indicate targets (rare tones and novel sounds combined), dashed/black lines indicate nontargets (rare tones and novel sounds combined). The gray line depicts the difference wave with its $95 \%$ confidence interval as determined by bootstrapping. Gray bars at the bottom of each graph indicate time intervals where the respective sources had significantly higher power in the target condition than in the nontarget condition. Source abbreviations: $v l F r=$ ventrolateral frontal; iflns=inferior frontal/insular; $\operatorname{PrCS}=$ precentral sulcus; $S T G=$ superior temporal gyrus; IPS = intraparietal sulcus; FrMed=medial frontal; postCing = posterior cingulate; $\mathrm{PrCu}=$ precuneus; $\mathrm{Cu}=$ cuneus .

\section{Novelty-processing}

Interestingly, bilateral middle superior temporal gyrus and right inferior frontal sulcus were observed to exhibit activation related to novelty-processing regardless of whether the novels were targets or nontargets. These findings replicate those of Opitz et al. (1999) who also reported bilateral temporal and right frontal activation in response to task-irrelevant novel sounds. However, while they observed right frontal activation only in subjects with a pronounced N4-like ERP component to identifiable novels, we found right inferior frontal activation related to novelty-processing in all subjects and regardless of whether the novel sounds were identifiable or not. This might be due to our use of an event-related design and the pseudo-randomized presentation of frequent tones, rare tones and novel sounds within one run. This may have underscored the "novelty" of the environmental sounds as compared to the block design of Opitz et al. where the novelty blocks consisted of only frequent tones and novel sounds. 
Nevertheless, the findings of their pioneering work and our results coincide with the data from other studies employing visual (Gur et al., 2007) or multimodal novelty oddball paradigms (Downar et al., 2002): In both these studies, right inferior frontal activation to novelty was observed. To some extent, the finding of substantial right inferior frontal activation in the novelty conditions also supports the model proposed by Corbetta and Shulman (2002), who propose a right lateralization of the ventral frontoparietal network involved in the detection of behaviorally relevant and salient or unexpected stimuli. Moreover, the right inferior frontal area has been implicated in processes of response inhibition by several authors (e.g. Chamberlain and Sahakian, 2007; Chikazoe et al., 2007; Robbins, 2007). Interestingly, a recent account of the functional significance of the novelty P3 holds that this component reflects the inhibition of a response engaged automatically when deviant events are detected (Goldstein et al., 2002). Taken together, these findings from diverse lines of research converge in the notion that the right inferior frontal cortex is crucially involved in processes underlying adaptive responses to novelty.

The ERP analyses showed that novel sounds evoked significantly higher amplitudes than rare tones in the novelty $\mathrm{P} 3 / \mathrm{P} 3 \mathrm{a}$ time range at frontocentral electrode sites, regardless of whether the novel sounds were targets or nontargets. This finding is in line with the results of Gaeta et al. (2003), who were the first to use a "reversed" novelty oddball and who observed that "the amplitude of the anterior aspect of the novelty P3 was greatest when elicited by environmental sounds regardless of whether they served as target or nontarget deviants (Gaeta et al., 2003, p. 206)".

Combining the AMRI and ERP data revealed additional insights into the neuroanatomical bases of novelty-processing. Overall, the fMRI-informed ERP source modeling findings parallel the fMRI results: In the novelty $\mathrm{P} 3$ time range, significantly higher source activation related to novelty-processing was observed mainly for frontal and temporal RSs. However, ERP source modeling did not support the fMRI-identified right lateralization of inferior frontal activation in novelty-processing but rather suggested bilateral frontal RS activation. Furthermore, in contrast to the fMRI result of primarily target-related activation of frontomedial areas, the frontomedial RS also contributed to novelty-processing-related ERP differences in the novelty P3 time window. This is in line with results from source localization studies suggesting a frontomedial contribution to the novelty P3 (Debener et al., 2005a; Dien et al., 2003).

\section{Target-processing}

fMRI activation distinctly related to target-processing was observed for frontomedial areas and for bilateral posterior middle frontal gyrus. Target-related activation was also found for right anterior middle frontal gyrus and right intraparietal sulcus, both of which regions had no clear target-related counterpart in the left hemisphere. Furthermore, the caudate nucleus as well as the culmen in the cerebellum bilaterally showed activation patterns related to target-processing.

The frontomedial ROI comprised superior portions of the anterior cingulate as well as premotor and supplementary motor regions, i.e. areas which are implicated in a variety of cognitive tasks. Although no overt response was required, the target-related activation of the frontomedial ROI may nevertheless be interpreted in terms of a response preparation process. This interpretation is supported by findings of Linden et al. (1999), who reported frontomedial activation in response to targets regardless of whether their participants had to respond to targets with a button press or with silent counting. While some studies reported frontomedial activation in response to distractor stimuli (e.g., Kiehl et al., 2001), the present findings are very similar to Bledowski et al. (2004a), who found frontomedial activation to be clearly target-related.

The bilateral posterior middle frontal gyrus ROIs were located near the frontal eye fields. Together with the target-related activation of the right intraparietal sulcus (and a possible target specificity also of the left intraparietal sulcus) observed in the present study, these findings conform with the dorsal frontoparietal network proposed by Corbetta and Shulman (2002) to be involved in top-down attentional processes.

Concerning the role of the caudate nucleus and the culmen with the latter showing the most distinct target-related activation pattern - our findings confirm those of Kiehl et al. (2001, 2005) who also observed strong bilateral activation of these regions in response to targets. While nucleus caudatus and cerebellum have traditionally been implicated in motor control, accumulating evidence also suggests an involvement of these areas in cognitive functions (e.g. Allen et al., 1997; Monchi et al., 2006). Future research on these regions' functional connectivity with cortical areas related to attention vs. motor control (see Allen et al., 2005 for cerebellar-prefrontal and -parietal connectivity) may help to further elucidate their role in target detection.

The ERP analyses showed that, corroborating the findings of Gaeta et al. (2003), targets evoked significantly higher amplitudes than nontargets in the $\mathrm{P} 3 \mathrm{~b}$ time range at parietal electrode sites only. However, the ERP source modeling analyses are only partially in line with the fMRI results on target-processing. In the P3b time range, almost all RSs showed more or less marked contributions to ERP differences related to target-processing. This was most pronounced for all medial RSs, but also for left frontal RSs. Possible reasons for these ambiguous findings will be discussed in detail in the following.

\section{Methodological issues}

Our analyses confirmed that ERPs of reasonable quality can be obtained inside the MR scanner (see Debener et al., 2007a,b for more details on data quality) and that the spatiotemporal patterns of ERPs commonly observed in novelty oddball paradigms, especially the novelty P3 and the P3b, as well as the direction of the task-related effects, are in line with previous outside scanner ERP studies both with (Debener et al., 2005a; Gaeta et al., 2003) and without (e.g. Debener et al., 2002; Strobel et al., 2004) alternating target instructions.

However, there are several discrepancies between the fMRI findings and the ERP source modeling results. A first, more technical explanation for these discrepancies regards the ERP signal-to-noise ratio (SNR). A comparison of the obtained ERPs with published data obtained outside the scanner clearly suggests that the SNR obtained from inside scanner ERP recordings was suboptimal in the present study. While the overall morphology and condition effects could be confirmed on the sensor level, the quality of ERP source modeling depends largely on the SNR of the data. In the present case, some of the subjects might have had an SNR that may be considered too low for accurate single subject source modeling. Hence, the goodness of fit of the source model, although being overall satisfactory (mean across subjects and 
conditions $\mathrm{RV}<20 \%$ ), was insufficient (RV>20\%) for several subjects.

Secondly, although fMRI and EEG signals both reflect synaptic activity (see e.g. Logothetis et al., 2001; Nunez and Silberstein, 2000), the correspondence between these signals may diverge, both temporally, as EEG and fMRI integrate synaptic activity at different time scales, and spatially, as it has been argued that the relation between ERPs and the BOLD response differs across brain regions (Huettel et al., 2004). Moreover, ERPs originating from partial phase-resetting of ongoing EEG activity might not induce major changes in local brain metabolism (Debener et al., 2006). In addition, ERPs reflect only the evoked fraction of the event-related EEG signal (Makeig et al., 2004), and, in light of the available evidence (Bénar et al., 2007; Debener et al., 2005b, Eichele et al., 2005), it is possible that event-related trial-by-trial fluctuations of the EEG signal which are not captured by the ERP contribute to the correlation with the BOLD signal. However, these issues clearly need further investigation. To date, it seems not well understood which fractions of the EEG and fMRI BOLD signals are related to each other and which are not.

These arguments, finally, also point towards inherent weaknesses in the fMRI-informed source modeling approach. Although it may be considered a straightforward approach towards addressing the inverse problem which has been applied successfully in other studies (e.g. Bledowski et al., 2004b, 2006; Heinze et al., 1994), it is important to keep in mind that, as Bledowski et al. (2006) pointed out, fMRI-informed source modeling can only assess the potential contribution of fMRI-derived ROIs to an ERP. The approach simply does not imply that each selected ROI is a necessary generator region of the respective ERPs. Rather, the approach limits the space of possible source configurations by showing which ROIs are unlikely to be source of a given ERP. For example, the observation that almost all RSs of our source model showed a contribution to the target $\mathrm{P} 3 \mathrm{~b}$ cannot be taken to indicate that they are obligatory generators of the P3b; it merely indicates some possibility for their contribution to the P3b. Hence, alternative approaches for EEG-fMRI integration, potentially informing beyond a mere correspondence between both techniques, may be considered in future studies (cf. Debener et al., 2006; Eichele et al., 2005).

\section{Conclusion}

The present study provides additional evidence for the "adaptive reflexive processing" model by Kiehl and colleagues by confirming a considerable overlap of brain areas recruited during bottom-up-and top-down-processing of behaviorally significant events. However, our study also revealed a number of brain regions that showed distinct activation patterns during novelty- and target-processing, emphasizing that depending on the behavioral significance of an event, different aspects of the attention-network are engaged. For bottom-up novelty-processing, both the fMRI findings and the source modeling results support a prominent role of temporal areas and inferior frontal regions (with a possible right-hemispheric dominance as revealed exclusively by fMRI). Target-related fMRI activation was confirmed in a distributed frontoparietal network, bilateral nucleus caudatus and cerebellum. Source modeling showed that most cortical regions identified by fMRI exhibited a contribution to target-related ERP signatures. Despite this latter ambiguity, the overall pattern of findings underscores the potential of simultaneous EEG/fMRI recordings for the spatiotemporal characterization of target- and novelty-processing.

\section{Acknowledgment}

A.S. was supported by a grant of the G.A. Lienert Foundation.

\section{References}

Alho, K., Winkler, I., Escera, C., Huotilainen, M., Virtanen, J., Jääskeläinen, I.P., Pekkonen, E., Ilmoniemi, R.J., 1998. Processing of novel sounds and frequency changes in the human auditory cortex: magnetoencephalographic recordings. Psychophysiology 35, 211-224.

Allen, G., Buxton, R.B., Wong, E.C., Courchesne, E., 1997. Attentional activation of the cerebellum independent of motor involvement. Science $275,1940-1943$.

Allen, P.J., Josephs, O., Turner, R., 2000. A method for removing imaging artifact from continuous EEG recorded during functional MRI. NeuroImage 12, 230-239.

Allen, G., McColl, R., Barnard, H., Ringe, W.K., Fleckenstein, J., Cullum, C.M., 2005. Magnetic resonance imaging of cerebellar-prefrontal and cerebellar-parietal functional connectivity. NeuroImage 15, 39-48.

Baudena, P., Halgren, E., Heit, G., Clarke, J.M., 1995. Intracerebral potentials to rare target and distractor auditory and visual stimuli: III. Frontal cortex. Electroencephalogr. Clin. Neurophysiol. 94, 251-264.

Bénar, C.G., Schön, D., Grimault, S., Nazarian, B., Burle, B., Roth, M., Badier, J.M., Marquis, P., Liegeois-Chauvel, C., Anton, J.L., 2007. Single-trial analysis of oddball event-related potentials in simultaneous EEG-fMRI. Hum. Brain Mapp. 28, 602-613.

Bledowski, C., Prvulovic, D., Goebel, R., Zanella, F.E., Linden, D.E.J., 2004a. Attentional systems in target and distractor processing: a combined ERP and fMRI study. NeuroImage 22, 530-540.

Bledowski, C., Prvulovic, D., Hoechstetter, K., Scherg, M., Wibral, M., Goebel, R., Linden, D.E.J., 2004b. Localizing P300 generators in visual target and distractor processing: a combined event-related potential and functional magnetic resonance imaging study. J. Neurosci. 24, 9353-9360.

Bledowski, C., Cohen Kadosh, K., Wibral, M., Rahm, B., Bittner, R.A., Hoechstetter, K., Scherg, M., Maurer, K., Goebel, R., Linden, D.E.J., 2006. Mental chronometry of working memory retrieval: a combined functional magnetic resonance imaging and event-related potentials approach. J. Neurosci. 26, 821-829.

Boynton, G.M., Engel, S.A., Glover, G.H., Heeger, D.J., 1996. Linear systems analysis of functional magnetic resonance imaging in human V1. J. Neurosci. 16, 4207-4221.

Chamberlain, S.R., Sahakian, B.J., 2007. The neuropsychiatry of impulsivity. Curr. Opin. Psychiatry 20, 255-261.

Chikazoe, J., Konishi, S., Asari, T., Jimura, K., Miyashita, Y., 2007. Activation of right inferior frontal gyrus during response inhibition across response modalities. J. Cogn. Neurosci. 19, 69-80.

Corbetta, M., Shulman, G.L., 2002. Control of goal-directed and stimulusdriven attention in the brain. Nat. Rev., Neurosci. 3, 201-215.

Daffner, K.R., Mesulam, M.M., Scinto, L.F., Acar, D., Calvo, V., Faust, R., Chabrerie, A., Kennedy, B., Holcomb, P., 2000. The central role of the prefrontal cortex in directing attention to novel events. Brain 123, 927-939.

Debener, S., Kranczioch, C., Herrmann, C.S., Engel, A.K., 2002. Auditory novelty oddball allows reliable distinction of top-down and bottom-up processes of attention. Int. J. Psychophysiol. 46, 77-84.

Debener, S., Makeig, S., Delorme, A., Engel, A.K., 2005a. What is novel in the novelty oddball paradigm? Functional significance of the novelty P3 event-related potential as revealed by independent component analysis. Brain Res. Cogn. Brain Res. 22, 309-321.

Debener, S., Ullsperger, M., Siegel, M., Fiehler, K., von Cramon, D.Y., Engel, A.K., 2005b. Trial-by-trial coupling of concurrent electroencephalogram 
and functional magnetic resonance imaging identifies the dynamics of performance monitoring. J. Neurosci. 25, 11730-11737.

Debener, S., Ullsperger, M., Siegel, M., Engel, A.K., 2006. Single-trial EEG-fMRI reveals the dynamics of cognitive function. Trends Cogn. Sci. 10, 558-563.

Debener, S., Strobel, A., Sorger, B., Peters, J., Kranczioch, C., Engel, A.K., Goebel, R., 2007a. Improved quality of auditory event-related potentials recorded simultaneously with 3-T fMRI: removal of the ballistocardiogram artefact. NeuroImage 34, 587-597.

Debener, S., Mullinger, K., Niazy, R.K., Bowtell, R.W., 2007b. Properties of the ballistocardiogram artefact as revealed by EEG recordings at 1.5, 3 and 7 Tesla static magentic field strength. Int. J. Psychophysiol. doi:10.1016/j.ijpsycho.2007.05.015.

Dien, J., Spencer, K.M., Donchin, E., 2003. Localization of the event-related potential novelty response as defined by principal components analysis. Brain Res. Cogn. Brain Res. 17, 637-650.

Donchin, E., Coles, M.G., 1988. Is the P300 component a manifestation of context updating? Behav. Brain Sci. 11, 357-374.

Downar, J., Crawley, A.P., Mikulis, D.J., Davis, K.D., 2002. A cortical network sensitive to stimulus salience in a neutral behavioral context across multiple sensory modalities. J. Neurophysiol. 87, 615-620.

Efron, B., Tibshirani, R.J., 1993. An Introduction to the Bootstrap. Chapman and Hall, New York.

Eichele, T., Specht, K., Moosmann, M., Jongsma, M.L.A., Quian Quiroga, R., Nordby, H., Hugdahl, K., 2005. Assessing the spatiotemporal evolution of neuronal activation with single-trial event-related potentials and functional MRI. Proc. Natl. Acad. Sci. U. S. A. 102, 17798-17803.

Escera, C., Alho, K., Schröger, E., Winkler, I., 2000. Involuntary attention and distractibility as evaluated with event-related brain potentials. Audiol. Neuro-otol. 5, 151-166.

Friedman, D., Cycowicz, Y.M, Gaeta, H., 2001. The novelty P3: an eventrelated brain potential (ERP) sign of the brain's evaluation of novelty. Neurosci. Biobehav. Rev. 25, 355-373.

Friston, K.J., Holmes, A.P., Poline, J.B., Grasby, P.J., Williams, S.C. Frackowiak, R.S., Turner, R., 1995. Analysis of fMRI time-series revisited. NeuroImage 2, 45-53.

Gaeta, H., Friedman, D., Hunt, G., 2003. Stimulus characteristics and task category dissociate the anterior and posterior aspects of the novelty P3. Psychophysiology 40, 198-208.

Goldstein, A., Spence, K.M., Donchin, E., 2002. The influence of stimulus deviance and novelty on the P300 and novelty P3. Psychophysiology 39, $781-790$.

Gur, R.C., Turetsky, B.I., Loughead, J., Waxman, J., Snyder, W., Ragland, J. D., Elliott, M.A., Bilker, W.B., Arnold, S.E., Gur, R.E., 2007. Hemodynamic responses in neural circuitries for detection of visual target and novelty: an event-related fMRI study. Hum. Brain Mapp. 28, 263-274.

Halgren, E., Baudena, P., Clarke, J.M., Heit, G., Liegeois, C., Chauvel, P., Musolino, A., 1995a. Intracerebral potentials to rare target and distractor auditory and visual stimuli: I. Superior temporal plane and parietal lobe. Electroencephalogr. Clin. Neurophysiol. 94, 191-220.

Halgren, E., Baudena, P., Clarke, J.M., Heit, G., Marinkovic, K., Devaux, B., Vignal, J.P., Biraben, A., 1995b. Intracerebral potentials to rare target and distractor auditory and visual stimuli: II. Medial, lateral and posterior temporal lobe. Electroencephalogr. Clin. Neurophysiol. 94, 229-250.

Heinze, H.J., Mangun, G.R., Burchert, W., Hinrichs, H., Scholz, M., Münte, T.F., Gos, A., Scherg, M., Johannes, S., Hundeshagen, H., Gazzaniga, M. S., Hillyard, S.A., 1994. Combined spatial and temporal imaging of brain activity during visual selective attention in humans. Nature 372, 543-546.

Herrmann, C.S., Knight, R.T., 2001. Mechanisms of human attention: event- related potentials and oscillations. Neurosci. Biobehav. Rev. 25, 465-476.

Hine, J., Debener, S., 2007. Late auditory evoked potentials asymmetry revisited. Clin. Neurophysiol. 118, 1274-1285.

Huettel, S.A., McKeown, M.J., Song, A.W., Hart, S., Spencer, D.D., Allison, T., McCarthy, G., 2004. Linking hemodynamic and electrophysiological measures of brain activity: evidence from functional MRI and intracranial field potentials. Cereb. Cortex 14, 165-173.

Kastner, S., Ungerleider, L.G., 2000. Mechanisms of visual attention in the human cortex. Annu. Rev. Neurosci. 23, 315-341.

Kiehl, K.A., Laurens, K.R., Duty, T.L., Forster, B.B., Liddle, P.F., 2001. An event-related fMRI study of visual and auditory oddball tasks. Int. J. Psychophysiol. 38, 133-142.

Kiehl, K.A., Stevens, M.C., Laurens, K.R., Pearlson, G., Calhoun, V.D., Liddle, P.F., 2005. An adaptive reflexive processing model of neurocognitive function: supporting evidence from a large scale $(n=100)$ fMRI study of an auditory oddball task. NeuroImage 25, 899-915.

Knight, R.T., 1984. Decreased response to novel stimuli after prefrontal lesions in man. Electroencephalogr. Clin. Neurophysiol. 59, 9-20.

Knight, R.T., 1996. Contribution of human hippocampal region to novelty detection. Nature 383, 256-259.

Kok, A., 2001. On the utility of P3 amplitude as a measure of processing capacity. Psychophysiology 38, 557-577.

Linden, D.E.J., Prvulovic, D., Formisano, E., Vollinger, M., Zanella, F.E., Goebel, R., Dierks, T., 1999. The functional neuroanatomy of target detection: an fMRI study of visual and auditory oddball tasks. Cereb. Cortex 9, 815-823.

Logothetis, N.K., Pauls, J., Augath, M., Trinath, T., Oeltermann, A., 2001. Neurophysiological investigation of the basis of the fMRI signal. Nature $412,150-157$.

Makeig, S., Debener, S., Onton, J., Delorme, A., 2004. Mining event-related brain dynamics. Trends Cogn. Sci. 8, 204-210.

Monchi, O., Petrides, M., Strafella, A.P., Worsley, K.J., Doyon, J., 2006. Functional role of the basal ganglia in the planning and execution of actions. Ann. Neurol. 59, 257-264.

Niazy, R.K., Beckmann, C.F., Iannetti, G.D., Brady, J.M., Smith, S.M., 2005. Removal of fMRI environment artifacts from EEG data using optimal basis sets. NeuroImage 28, 720-737.

Nunez, P.L., Silberstein, R.B., 2000. On the relationship of synaptic activity to macroscopic measurements: does co-registration of EEG with $\mathrm{fMRI}$ make sense? Brain Topogr. 13, 79-96.

Opitz, B., Mecklinger, A., Friederici, A.D., von Cramon, D.Y., 1999. The functional neuroanatomy of novelty processing: integrating ERP and fMRI results. Cereb. Cortex 9, 379-391.

Robbins, T.W., 2007. Shifting and stopping: fronto-striatal substrates, neurochemical modulation and clinical implications. Philos. Trans. R. Soc. Lond., B Biol. Sci. 362, 917-932.

Scherg, M., von Cramon, D., 1986. Evoked dipole source potentials of the human auditory cortex. Electroencephalogr. Clin. Neurophysiol. 65 $344-360$.

Schneider, T.R., Debener, S., Engel, A.K., 2008. Multisensory identification of natural objects in a two-way crossmodal priming paradigm. Exp. Psychol. 55, 121-132.

Spencer, K.M., Dien, J., Donchin, E., 2001. Spatiotemporal analysis of the late ERP responses to deviant stimuli. Psychophysiology 38, 343-358.

Strobel, A., Debener, S., Anacker, A., Müller, J., Lesch, K.-P., Brocke, B., 2004. Dopamine D4 receptor exon III genotype influence on the auditory evoked novelty P3. NeuroReport 15, 2411-2415.

Talairach, J., Tournoux, P., 1988. Co-Planar Stereotaxic Atlas of the Human Brain. Thieme, Stuttgart. 